\title{
Retrospective EI Niño Forecasts Using an Improved Intermediate Coupled Model
}

\author{
Rong-Hua Zhang* and Stephen E. Zebiak \\ International Research Institute for Climate Prediction, The Earth Institute at Columbia University, Palisades, New York
}

\section{RichARD KLEEMAN}

Courant Institute for Mathematical Sciences, New York University, New York, New York

\author{
Noel KeENLyside
}

Institut fuer Meereskunde, Kiel, Germany

(Manuscript received 7 June 2004, in final form 27 January 2005)

\begin{abstract}
A new intermediate coupled model (ICM) is presented and employed to make retrospective predictions of tropical Pacific sea surface temperature (SST) anomalies. The ocean dynamics is an extension of the McCreary baroclinic modal model to include varying stratification and certain nonlinear effects. A standard configuration is chosen with 10 baroclinic modes plus two surface layers, which are governed by Ekman dynamics and simulate the combined effects of the higher baroclinic modes from 11 to 30 . A nonlinear correction associated with vertical advection of zonal momentum is incorporated and applied (diagnostically) only within the two surface layers, forced by the linear part through nonlinear advection terms. As a result of these improvements, the model realistically simulates the mean equatorial circulation and its variability. The ocean thermodynamics include an SST anomaly model with an empirical parameterization for the temperature of subsurface water entrained into the mixed layer $\left(T_{e}\right)$, which is optimally calculated in terms of sea surface height ( $\mathrm{SSH}$ ) anomalies using an empirical orthogonal function (EOF) analysis technique from historical data. The ocean model is then coupled to a statistical atmospheric model that estimates wind stress $(\tau)$ anomalies based on a singular value decomposition (SVD) analysis between SST anomalies observed and $\tau$ anomalies simulated from ECHAM4.5 (24-member ensemble mean). The coupled system exhibits realistic interannual variability associated with El Niño, including a predominant standing pattern of SST anomalies along the equator and coherent phase relationships among different atmosphere-ocean anomaly fields with a dominant 3-yr oscillation period.

Twelve-month hindcasts/forecasts are made during the period 1963-2002, starting each month. Only observed SST anomalies are used to initialize the coupled predictions. As compared to other prediction systems, this coupled model has relatively small systematic errors in the predicted SST anomalies, and its SST prediction skill is apparently competitive with that of most advanced coupled systems incorporating sophisticated ocean data assimilation. One striking feature is that the model skill surpasses that of persistence at all lead times over the central equatorial Pacific. Prediction skill is strongly dependent on the season, with the correlations attaining a minimum in spring and a maximum in fall. Cross-validation experiments are performed to examine the sensitivity of the prediction skill to the data periods selected for training the empirical $T_{e}$ model. It is demonstrated that the artificial skill introduced by using a dependently constructed $T_{e}$ model is not significant. Independent forecasts are made for the period 1997-2002 when no dependent data are included in constructing the two empirical models $\left(T_{e}\right.$ and $\left.\tau\right)$. The coupled model has reasonable success in predicting transition to warm phase and to cold phase in the spring of 1997 and 1998, respectively. Potential problems and further improvements are discussed with the new intermediate prediction system.
\end{abstract}

* Current affiliation: Earth System Science Interdisciplinary Center, University of Maryland, College Park, College Park, Maryland.

Corresponding author address: Rong-Hua Zhang, ESSIC, Computer and Space Science Building \#224, University of Maryland, College Park, College Park, MD 20742.

E-mail: rzhang@essic.umd.edu

(C) 2005 American Meteorological Society 


\section{Introduction}

In the past two decades, El Niño studies have made remarkable progress, reaching the stage where skillful predictions can be made 6-12 months in advance. Several forecast systems have been used routinely in real time to do so. These include statistical models (e.g., Barnston and Ropelewski 1992) and physical coupled models of varying degrees of complexity, ranging from intermediate coupled models (ICMs; e.g., Cane et al. 1986; Zebiak and Cane 1987, hereafter ZC87; Kleeman 1993; Zhang et al. 2003), to hybrid coupled models (e.g., Barnett et al. 1993; Syu et al. 1995; Tang and Hsieh 2002), to coupled general circulation models (GCMs) (e.g., Ji et al. 1996; Rosati et al. 1997; Kirtman et al. 2002).

Large systematic biases are still a problem in many coupled models (e.g., Latif et al. 2001), and significant intermodel differences exist in sea surface temperature (SST) simulation and prediction (e.g., Barnett et al. 1993; Chen et al. 2000). The skill of SST prediction in the equatorial Pacific is strongly model dependent and widely divergent across various coupled prediction systems (e.g., Latif et al. 1998; Barnston et al. 1999). To improve prediction skill, intensive efforts have been made in model development, coupled initialization, ocean data assimilation, and bias correction. In particular, through continued improvements (Chen et al. 1995, 2000; Kang and Kug 2000), ICMs remain competitive with more complex models and offer great promise for further advancing seasonal-to-interannual climate prediction associated with El Niño in the tropical Pacific.

However, traditional intermediate ocean models (e.g., Busalacchi and O'Brien 1980; ZC87) include only a few baroclinic modes (often one) and neglect nonlinearity in the momentum equations. As a result, the simulation of SST variability in the central Pacific, where zonal advection is an important term in the heat budget (e.g., Ji et al. 1996), may be poor in these models. Increasing the number of baroclinic modes in these models improves the vertical structure of equatorial currents significantly (McCreary 1981). But, surface currents become unrealistically strong, since nonlinear terms are neglected. With this in mind, Keenlyside and Kleeman (2002) developed a new intermediate ocean model: the model is an extension of the McCreary (1981) baroclinic model to include varying stratification and partial nonlinearity effects. As a direct result of these extensions the model is able to realistically simulate the mean upper-ocean equatorial circulation and its variability (Keenlyside 2001; Keenlyside and Kleeman 2002).
Another problem area in ICMs is the parameterization of $T_{e}$ anomalies for use in the calculation of SST anomalies in terms of dynamical ocean quantities. Most commonly a local parameterization is used; however there is evidence that $T_{e}$ variability has a nonlocal character (Zhang et al. 2005), and that this also contributes to the deficiencies of these models in simulating SST anomalies over the central basin (e.g., ZC87; Keenlyside 2001). With this motivation, Zhang et al. (2005) developed a nonlocal empirical parameterization of $T_{e}$. First, $T_{e}$ anomaly fields are estimated by inverting the SST anomaly equation using observed SST and simulated upper-ocean currents. This approach, thus, by giving a balanced treatment of various terms in the heat budget of the mixed layer, provides an optimized estimate of $T_{e}$ anomalies for use in simulating SST anomalies. Second, a relationship between the estimated $T_{e}$ and modeled sea surface height (SSH) interannual variability is constructed based on a regression of their historical time series in a reduced space of empirical orthogonal functions (EOFs). Finally, given a SSH anomaly, $T_{e}$ can be parameterized and used for SST anomaly calculations. With these improvements the Keenlyside and Kleeman (2002) intermediate ocean model simulates SST interannual variability in the tropical Pacific very well (Zhang et al. 2005).

The improved ocean model is coupled to an empirical atmospheric model constructed from a singular value decomposition (SVD) of the covariance between SST and wind stress anomalies. The coupled system exhibits quite realistic interannual variability associated with El Niño, which suggests realistic development of coupled modes within the tropical Pacific atmosphereocean system, which in principle should yield better El Niño predictions. In this paper, we explore the model's ability to predict tropical Pacific SST anomalies. Since the ICM places very low demands on computing resources, a large number of predictions have been made for retrospective El Niño forecasts. One particular focus will be on examining the sensitivity of prediction skill to the $T_{e}$ model constructed from historical data, since this is one of the most significant distinguishing features of this new coupled model.

The paper is organized as follows. Section 2 describes briefly model components and various datasets used; section 3 provides a description of the performance of their uncoupled and coupled simulations. A simple initialization procedure is presented in section 4 . Section 5 demonstrates the hindcast skill of the coupled system. Section 6 presents verification experiments, and section 7 deals with an independent forecast experiment for the period 1997-2002. The paper is concluded in section 8 . 


\section{Description of model components and datasets}

In this section, we briefly describe various components of the new ICM (Fig. 1). Readers can find more information on the model's dynamical component in Keenlyside (2001) and Keenlyside and Kleeman (2002), and on the model's improved empirical $T_{e}$ parameterization scheme in Zhang et al. (2003, 2005).

\section{a. The dynamical ocean model}

The dynamical component of the intermediate complexity ocean model, developed by Keenlyside and Kleeman (2002), consists of a linear and a nonlinear component. The linear dynamics of the model follow the modal formulation of McCreary (1981), but are extended to have horizontally varying background stratification. A standard configuration is chosen with 10 baroclinic modes plus two surface layers, which are governed by Ekman dynamics and simulate the combined effects of the higher baroclinic modes from 11 to 30. A nonlinear correction associated with vertical advection of zonal momentum is incorporated and applied diagnostically only within the two surface layers, forced by the linear part through nonlinear advection terms. The linear and nonlinear components produce dynamical ocean variables, including horizontal currents over the surface mixed layer, vertical velocity at the base of the mixed layer (entrainment velocity), and ocean pressure fields.

The ocean model domain extends from $33.5^{\circ} \mathrm{S}$ to $33.5^{\circ} \mathrm{N}$ and from $124^{\circ}$ to $30^{\circ} \mathrm{E}$, covering the tropical Pacific and Atlantic basins with a realistic representation of continents. (Only results from the Pacific basin are presented in this paper.) The model has a $2^{\circ}$ zonal grid spacing and a meridional grid stretching from $0.5^{\circ}$ within $10^{\circ}$ of the equator to $3^{\circ}$ at the northern and southern boundaries. Vertically, a 5500-m flat-bottom ocean is assumed; the linear component has 33 levels, chosen as in Levitus (1982), with 8 levels in the upper $125 \mathrm{~m}$. The two layers used to simulate the nonlinear effects and high-order baroclinic modes span the upper $125 \mathrm{~m}$ and are divided by a surface mixed layer whose depth is prescribed from observations. Details of the model configuration and parameters are given by Keenlyside (2001) and Keenlyside and Kleeman (2002).

\section{b. An SST anomaly model with an empirical parameterization for $T_{e}$}

An SST anomaly model is embedded within this dynamic construct. Its governing equation describes the evolution of mixed-layer temperature anomalies,

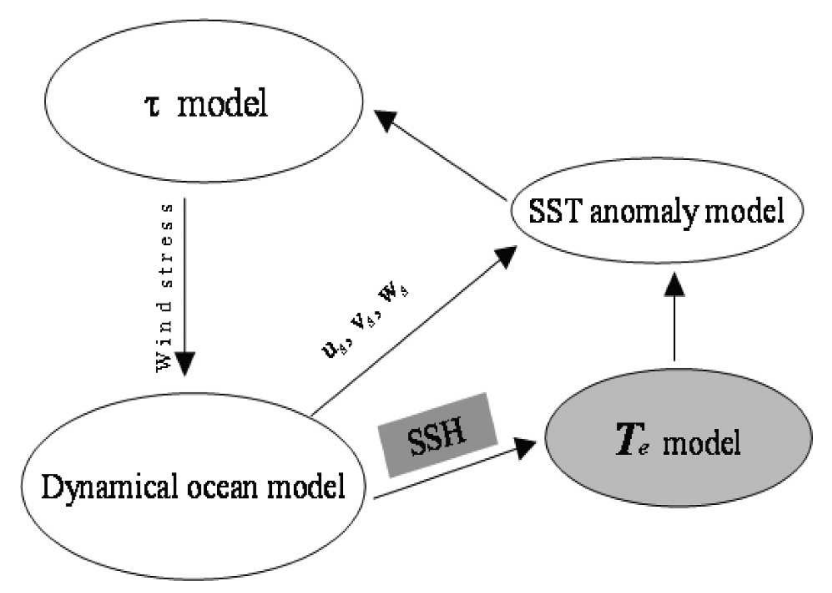

FIG. 1. A schematic illustrating an intermediate coupled atmosphere-ocean model consisting of a dynamical ocean model, an SST anomaly model with an empirical parameterization for $T_{e}$ in terms of SSH, and a statistical atmospheric wind stress $(\tau)$ model.

among others, determined by ocean horizontal and vertical advections associated with both mean and anomalous currents produced by the dynamical ocean model (Keenlyside 2001).

It has been well known that subsurface processes at the base of the surface mixed layer (entrainment and mixing) are important in controlling SST variability in the central and eastern equatorial Pacific where the thermocline is shallow and the mean upwelling is strong (e.g., ZC87; Kang and Kug 2000). A crucial component for realistic SST anomaly simulation is, therefore, the determination of the temperature of subsurface water entrained into the mixed layer $\left(T_{e}\right)$, which is associated with two terms: entrainment by upwelling and the vertical mixing between the surface mixed layer and subsurface layer. Since subsurface temperature field is not available from the ocean dynamical model, $T_{e}$ has to be parameterized for use in the embedded SST anomaly model in terms of other ocean dynamic quantities, as in ZC87.

An empirical $T_{e}$ model has been developed that parameterizes entrainment and vertical mixing processes associated with the subsurface temperature anomalies (Zhang et al. 2003, 2005). Since its geographic distribution and temporal evolution are not available from observations, an inverse modeling method is first adopted to estimate $T_{e}$ anomalies using an SST anomaly equation, observed SST variability, and simulated mean and anomaly currents from the ocean model. In so doing, for a given SST anomaly equation, the inverted $T_{e}$ anomalies yield an optimized estimate of $T_{e}$ for use in simulating SST anomalies by balancing various terms in the heat budget of the mixed layer.

Then, a relationship between the so-determined $T_{e}$ 


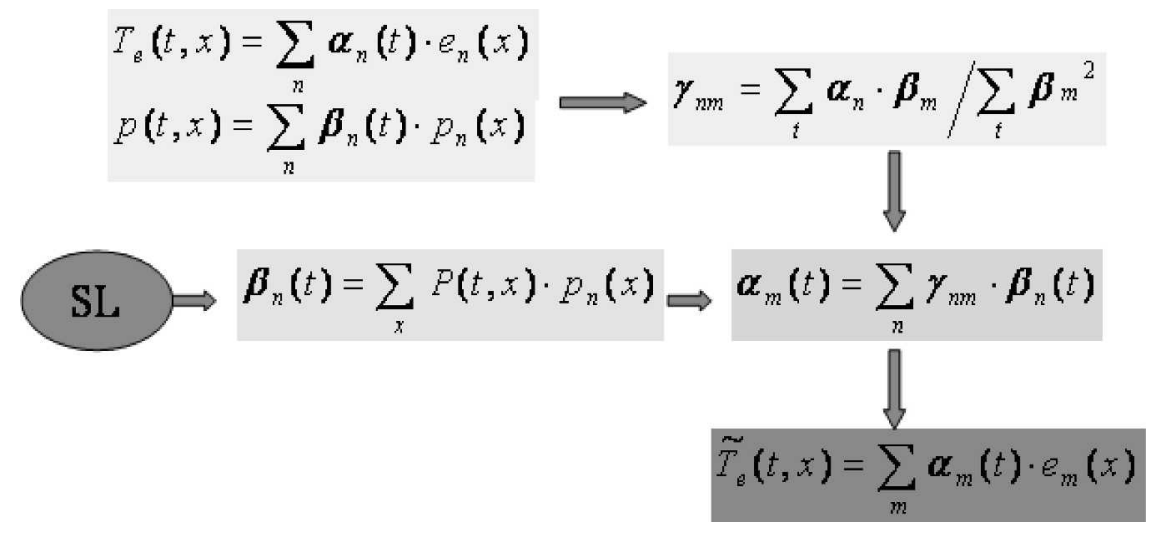

FIG. 2. A schematic showing a statistical method to estimate $T_{e}$ anomalies from a given $\mathrm{SSH}$ anomaly by an EOF analysis technique.

anomalies and simulated SSH anomalies (a prognostic field from the ocean model) is obtained by using an EOF analysis technique. The physical basis is the fact that thermocline fluctuations in response to atmospheric winds are a primary source of interannual temperature variability throughout the upper ocean in the equatorial Pacific (e.g., Cane et al. 1986; ZC87; Neelin and Jin 1993; Jin and An 1999). Characterized by the vertical displacement of the thermocline, the ocean dynamical signal forced by atmospheric winds propagates very quickly within the equatorial waveguide, remotely generating a thermodynamic response at the base of the mixed layer. When the subsurface temperature anomalies associated with thermocline displacement are created at depth, SST variability can be produced through the entrainment of subsurface water into the mixed layer and/or mixing between the subsurface and surface layers. Indeed, observations further indicate that variations in SSH and the thermocline are well correlated over the equatorial Pacific (e.g., Wang and McPhaden 2000) and that subsurface temperature anomalies associated with thermocline displacements are closely related with SSH variability. These observations and modeling studies provide a statistical basis for inferring subsurface temperature anomalies from SSH variability. Furthermore, modeling studies demonstrated that SSH and thermocline depth variability can be relatively well simulated even in simple ocean models (e.g., linear, one-vertical-mode model) forced by observed wind stress anomalies (e.g., McCreary and Anderson 1991; Busalacchi and O'Brien 1980).

So, a historical data-based empirical relation between $T_{e}$ and SSH anomalies is developed to estimate $T_{e}$ anomalies in terms of SSH anomalies. Such approaches have been used successfully to construct wind stress anomalies from a given SST anomaly in many tropical coupled atmosphere-ocean models (e.g., Bar- nett et al. 1993). To determine statistically optimized empirical modes of interannual variability between $T_{e}$ and SSH, an EOF analysis technique is adopted for calculating the relationship between $\mathrm{SSH}$ and $T_{e}$ interannual variations (e.g., Barnett et al. 1993).

More specifically, the procedure with the EOF-based statistical scheme is as follows (Fig. 2). Monthly $T_{e}$ and SSH anomaly data are first normalized by dividing their spatially averaged standard deviation to form the variance matrix with which an EOF decomposition is made into dominant spatial modes $\left(e_{n}\right.$ and $\left.p_{n}\right)$ and the corresponding time series (principal components; $\alpha_{n}$ and $\beta_{n}$ ). The latter are then used to obtain a matrix of regression coefficients relating the two fields $\left(\gamma_{n m}\right)$. Thus, a given SSH anomaly field can be converted into a $T_{e}$ anomaly using the derived spatial EOF modes $\left(e_{m}\right)$ and temporal regression coefficients $\left(\alpha_{m}\right)$.

Two EOF calculations are possible. One is called the seasonally invariant version (annual model): the EOF analysis is performed on all time series data irrespective of season. Another is called the seasonally varying version (monthly model): the EOF analysis is performed separately for each calendar month to construct seasonally dependent models, giving $12 T_{e}$ models, one for each calendar month. In this paper, we adopt the latter.

The SST anomaly model has the same grid as the dynamical ocean component. At each time step, the dynamical ocean model produces upper-ocean current anomalies and SSH anomalies; $T_{e}$ anomalies are then estimated from the latter. These current and $T_{e}$ anomalies, together with a prescribed climatology of mean currents from the model and thermal fields from observations, are passed to the SST anomaly model to calculate its own evolution. As has been demonstrated by Zhang et al. (2003, 2005), the empirical $T_{e}$ parameterization can significantly improve SST anomaly simulation and prediction in the ICM. 
(a) SST anomalies

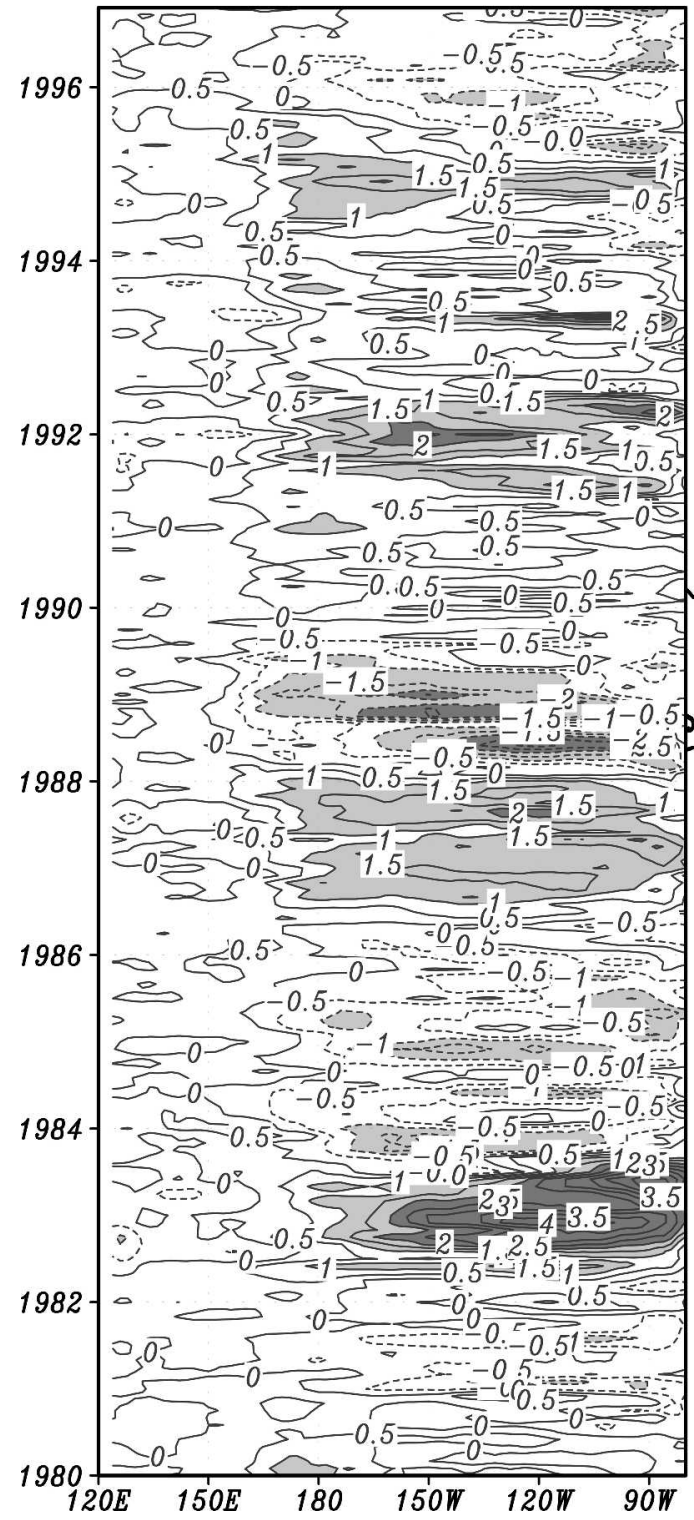

(b) Taux anomalies (NCEP-NCAR)

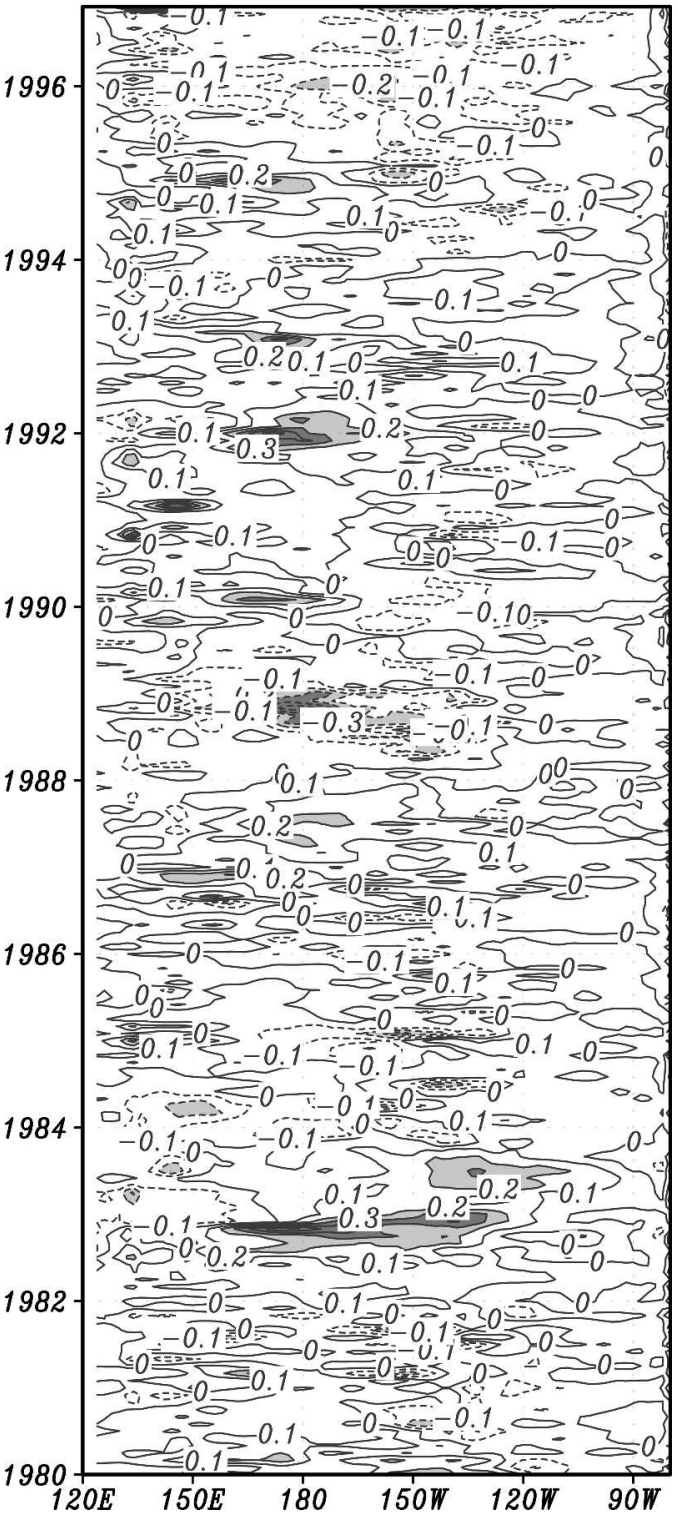

FIG. 3. Anomalies along the equator of (a) SST from Reynolds et al. (2002) and (b) zonal wind stress from the NCEP-NCAR reanalysis. The contour interval is $0.5^{\circ} \mathrm{C}$ in (a) and 0.1 dyn $\mathrm{cm}^{-2}$ in (b), respectively.

\section{c. The statistical atmospheric model}

The atmospheric model adopted in this work is also statistical, specifically relating wind stress $(\tau)$ and SST anomaly fields. The $\tau$ model is constructed from an SVD of the covariance matrix that is calculated from time series of monthly mean SST and $\tau$ fields (e.g., Syu et al. 1995; Chang et al. 2001). In this work, we perform a combined SVD analysis of the covariance among anomalies of SST, zonal, and meridional wind stress components.

\section{d. Datasets and analysis procedures}

Various observational and simulated data are needed to construct the two empirical models $\left(\tau\right.$ and $T_{e}$ ) and to verify model simulations. Observed SST data are from Reynolds et al. (2002). Monthly wind stress data are from the National Centers for Environmental Prediction-National Center for Atmospheric Research (NCEP-NCAR) reanalysis (Kalnay et al. 1996). An example of these interannual anomalies is shown in Fig. 3 for the observed SST and zonal wind stress anomalies 
along the equator during the period 1980-96. These data are used to construct the empirical $T_{e}$ model.

In addition, wind stress data used to construct the $\tau$ model are the ensemble mean of a 24-ensemble member ECHAM4.5 simulation of the period 1950-99, forced by observed SST anomalies. Using the ensemble mean data is an attempt to enhance the SST-forced signal by reducing atmospheric noise.

Historical SSH and current anomalies for the period 1962-99 are obtained from the dynamical ocean-only integration forced by interannual wind stress anomalies from the NCEP-NCAR reanalysis; the mean ocean currents are also obtained from the dynamical oceanonly simulation forced by climatological NCEP-NCAR winds. Historical $T_{e}$ anomalies are estimated by inverse modeling as follows. First, a relation for $T_{e}$ in terms of SST, SST gradients, and ocean currents is obtained by inverting the SST anomaly equation. Then, this relation is applied using monthly mean simulated ocean currents and observed SST anomalies (Fig. 3a of Reynolds et al. 2002) to estimate $T_{e}$ for the period 1962 to 1999.

These observed and/or derived anomaly fields are used to construct the two empirical models during the period 1963-96 (34 yr of data). As demonstrated by Barnett et al. (1993) and Syu and Neelin (2000), the seasonality of the atmosphere and the ocean can have an important effect on the onset and evolution of El Niño. Thus, to construct seasonally dependent models for $T_{e}$ and $\tau$, the EOF and SVD analyses are performed separately for each calendar month (a total of 34 temporal samples), and so both models consist of 12 different submodels, one for each calendar month. To achieve reasonable amplitudes, the first five EOF (SVD) modes are retained in estimating $T_{e}(\tau)$ fields from SSH (SST) anomalies.

\section{e. The coupling procedure}

All coupled model components exchange simulated anomaly fields (Fig. 1). At each time step, the dynamical ocean component produces anomalous ocean pressure, mixed-layer averaged currents, and vertical velocity at the base of the mixed layer (entrainment). Then from the SSH anomaly, a $T_{e}$ anomaly is calculated with the EOF-based $T_{e}$ model, serving as an interface between the SST anomaly and dynamical model components. The SST anomaly model then takes the $T_{e}$ and ocean circulation fields (prescribed mean and simulated), and the observed climatologies of mean SST and vertical temperature gradient to update the SST anomaly. The resultant SST anomaly is then used to calculate wind stress anomalies with the SVD-based $\tau$ model. These are then used to force the dynamical ocean model on the next time step. Information between the atmosphere $(\tau)$ and the ocean (SST) is exchanged once a day, and the $T_{e}$ anomalies for the SST anomaly model are also updated once a day from the SSH anomalies.

In this coupled system, empirical models determine two forcing fields: $\tau$ for the dynamical ocean model, and $T_{e}$ for the SST anomaly model. The amplitude and/or structure of $T_{e}$ and $\tau$ anomalies produced can be further modified before being used to force the corresponding component models. For example, as examined previously by numerous studies (e.g., Barnett et al. 1993; Syu et al. 1995), coupled behaviors depend on the so-called relative coupling coefficient $(\boldsymbol{\alpha})$, that is, wind stress anomalies from the $\tau$ model can be further multiplied by a scalar parameter before being used to drive the ocean model. Similarly, $T_{e}$ anomalies from the $T_{e}$ model can also be multiplied by a scalar parameter $(\beta)$ before being used in the SST anomaly model, commonly referred to as the thermocline coefficient (e.g., Neelin and Jin 1993). Several tuning experiments have been performed with different values of $\alpha$ and $\beta$ to examine their effects on coupled interannual variability: $\alpha=1.0$ and $\beta=1.0$ produce weak anomalies of SST and $\tau$ in the coupled model; $\alpha=1.05$ and $\beta=1.0$ produce a reasonable interannual variability with an oscillation period of $3 \mathrm{yr}$. In this paper, we choose $\alpha=$ 1.05 and $\beta=1.0$ in all experiments shown below.

\section{Uncoupled and coupled model performances}

In this section, the model performances in uncoupled and coupled simulations, which form the basis for the prediction experiments presented in next sections, are reviewed briefly.

\section{a. The $T_{e}$ parameterization}

Figure 4 displays the simulated SSH and estimated $T_{e}$ anomalies along the equator for the period 1980-90. Large interannual variability associated with El Niño and La Niña events can be seen. SSH has clear eastward propagation along the equator, with large anomalies both in the east and in the west; $T_{e}$ variability, reflecting a thermodynamic response, is predominately concentrated in the central and eastern basin. There exists a coherent relationship between SSH and $T_{e}$ anomalies in the equatorial region. East of the date line, $T_{e}$ variations closely follow those in SSH. When an SSH anomaly signal propagates eastward along the equator, $T_{e}$ anomalies can be seen to emerge almost instantaneously east of the date line. This indicates that dy- 
(a) SSH from dynamic model

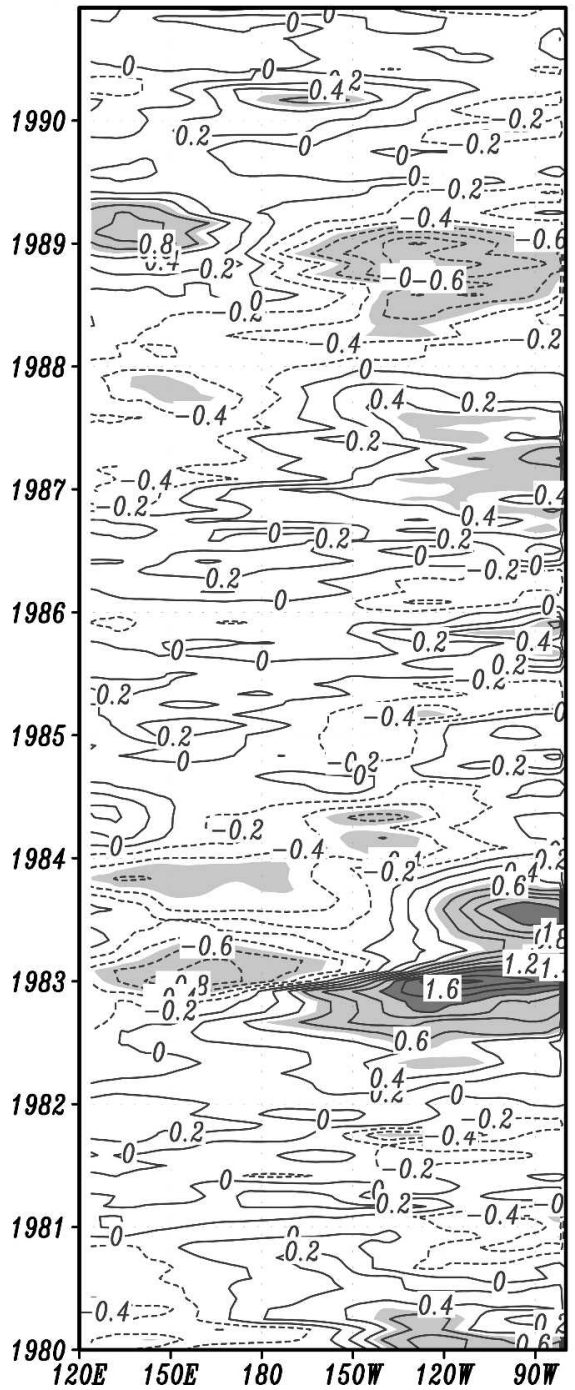

(b) Te from inverse modeling

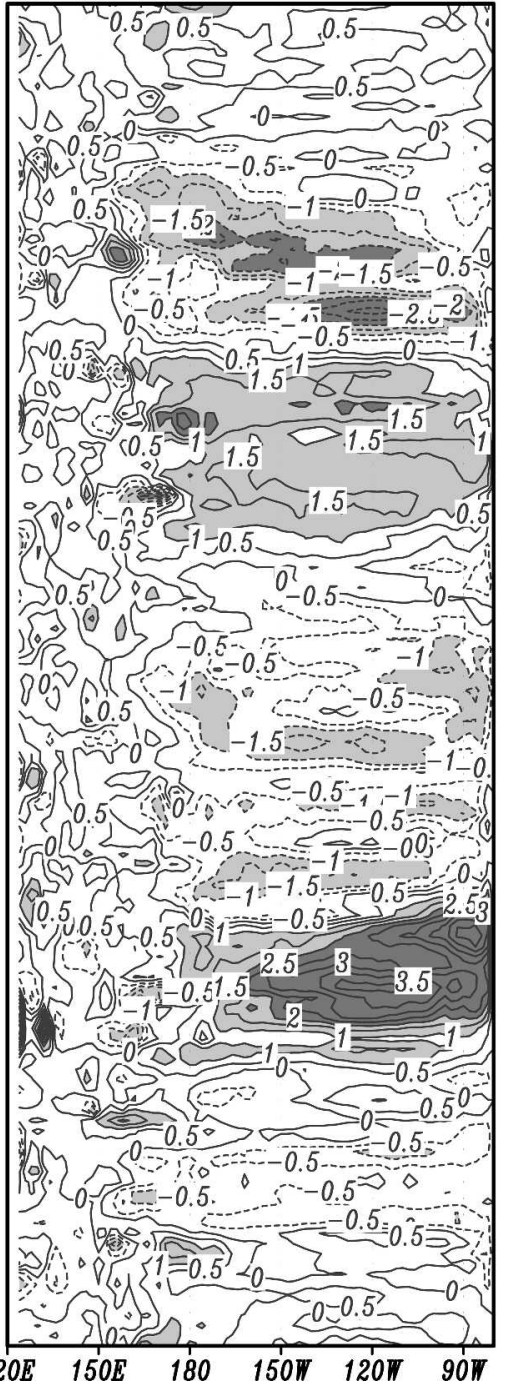

(c) Reconstructed Te from SSH

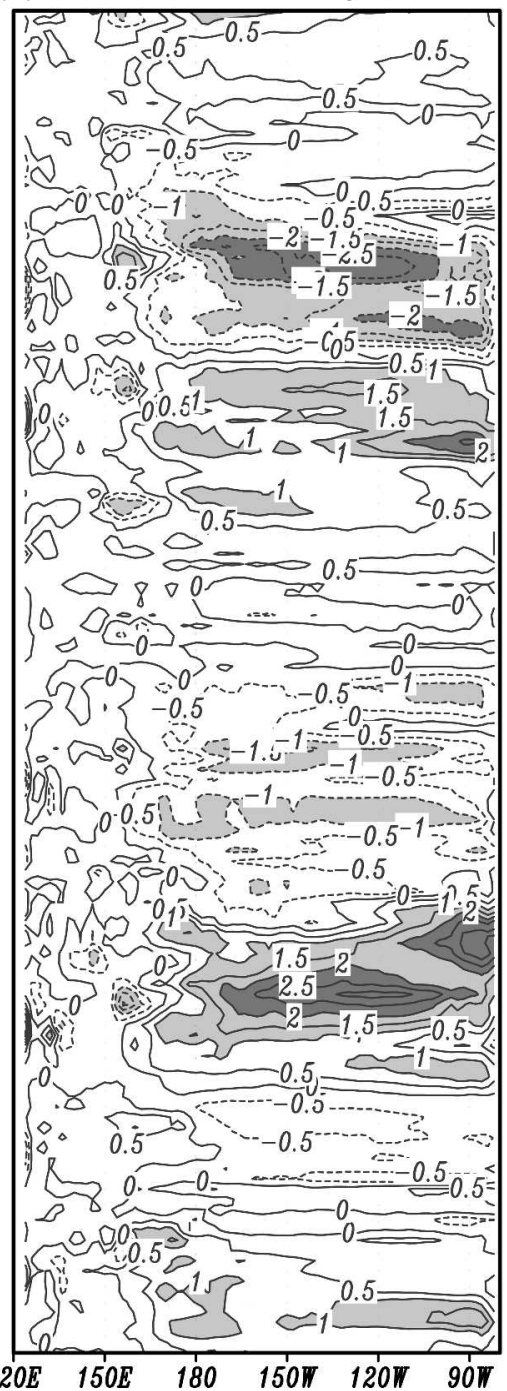

FIG. 4. Lon-time sections along the equator of (a) SSH anomalies, (b) $T_{e}$ anomalies derived via the inverse calculation from the SST anomaly equation, and (c) reconstructed via an EOF-based empirical $T_{e}$ model from the SSH anomalies, respectively. The contour interval is $0.2 \mathrm{~m}^{2} \mathrm{~s}^{-2}$ in (a) and $0.5^{\circ} \mathrm{C}$ in (b) and (c).

namic adjustment is playing an important role in generating $T_{e}$ variability over the central and eastern equatorial Pacific. Furthermore, relative to SSH variations, a delayed response of $T_{e}$ is evident over the central basin. For example, after the height of the 1982/83 El Niño, although SSH anomalies become negative in the central basin (Fig. 4a), large warm $T_{e}$ anomalies persist there for more than 3 months (Fig. 4b).

An EOF analysis is performed for the period 1963-96 to get eigenvectors and the corresponding time coefficients from modeled time series of monthly mean $T_{e}$ and $\mathrm{SSH}$ anomalies. Figure 5 shows the spatial patterns of the first EOF mode and its associated time series. The temporal expansion coefficients (Fig. 5c) clearly indicate that the first mode describes interannual variability associated with El Niño and La Niña events. The spatial structure represents the pattern of large-scale variability at the height of El Niño or La Niña events. Clear differences are evident in the spatial structure of interannual anomalies between $\mathrm{SSH}$ and $T_{e}$. SSH variability is characterized by a seesaw pattern across the basin: one center is located in the eastern equatorial Pacific, the other in the northwestern Pacific at $10^{\circ} \mathrm{N}$. The $T_{e}$ variability has one center of variability over the central and eastern equatorial Pacific. The SSH and $T_{e}$ centers of variability are not collocated, indicating a nonlocal nature of their space-time evolution.

A seasonally varying $T_{e}$ model is then constructed 
(a) Spatial pattern of SSH anomalies

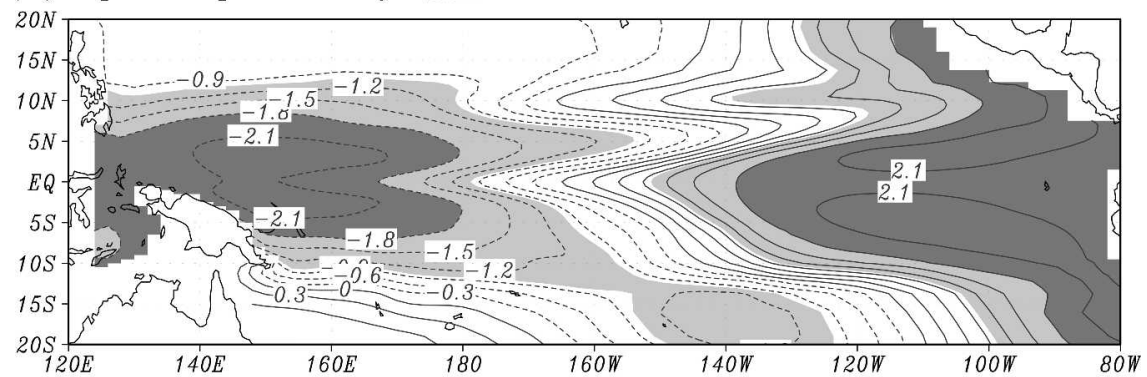

(b) Spatial pattern of Te anomalies

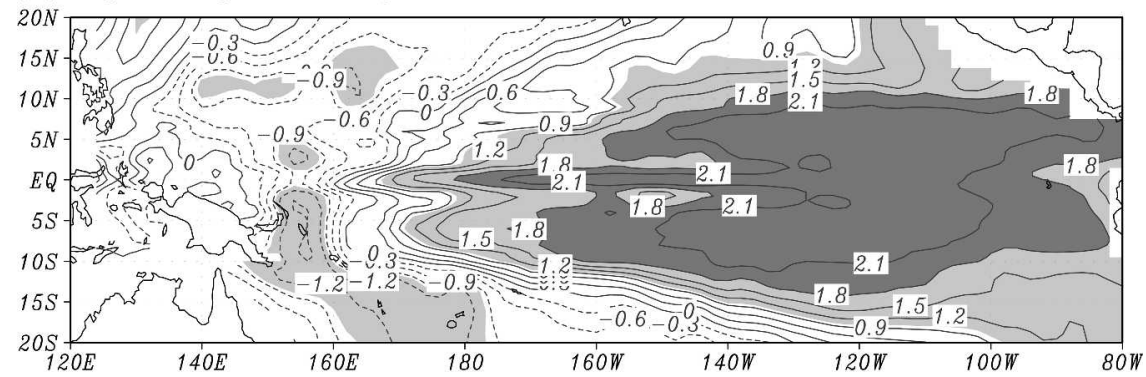

(c) Expansion coefficients

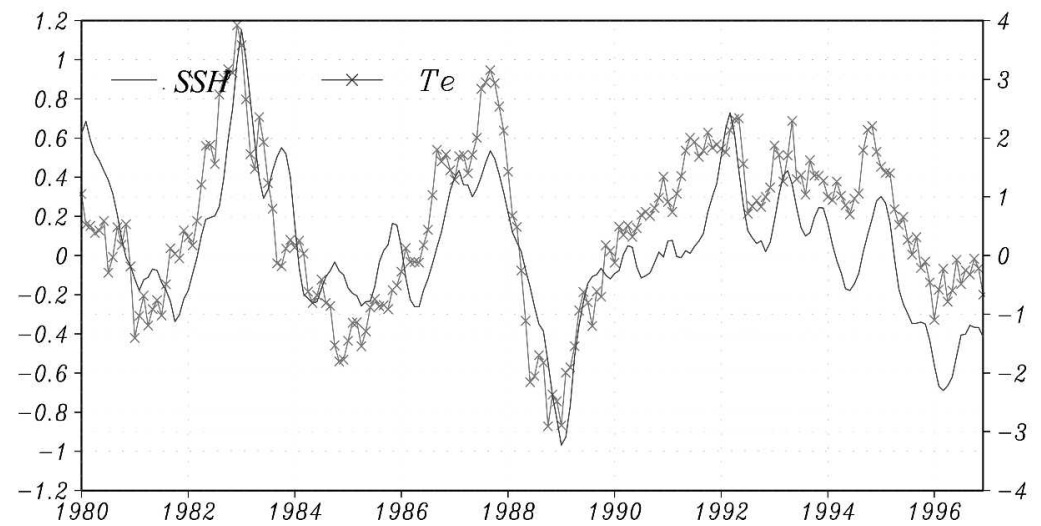

FIG. 5. Spatial patterns of the first EOF mode for (a) SSH and (b) $T_{e}$, and (c) their associated time series, respectively. The EOF analysis is performed on normalized time series of SSH and $T_{e}$ anomalies during the period 1963-96. The contour interval is 0.3 in (a) and (b).

from the EOF analysis using linear regression (Fig. 2). The reconstructed $T_{e}$ anomalies (Fig. 4c) compare very well to the original fields (Fig. 4b). With the five modes included, the amplitude of the reconstructed $T_{e}$ anomalies is comparable to the original field (Fig. $4 \mathrm{~b}$ ), but the anomalies are somewhat smoothed with less noise, indicating that the selected EOF modes effectively act as a low-pass filter. Thus, the first five EOF modes appear to be sufficient to recover the anomaly strength at a reasonable level.

\section{b. Uncoupled interannual variability}

As described above, the $\tau$ model is constructed from the ECHAM4.5 ensemble simulations and observed
SST via an SVD analysis for the periods 1963-96. Then, given an SST anomaly, wind stress anomalies can be estimated correspondingly. Figure $6 a$ demonstrates the reconstructed zonal wind stress variability from the observed SST anomalies (Fig. 3a). Good agreement can be seen with the NCEP-NCAR reanalysis wind stress data (Fig. 3b). In particular, zonal wind anomalies exhibit realistically the eastward propagation along the equator during the onset of El Niño events (Fig. 6a).

Furthermore, to see whether observed SST variability can be realistically simulated with the ECHAM4.5based wind stress anomalies, another interannual simulation is performed to simulate SST anomalies using the empirical $T_{e}$ model constructed from the NCEP- 
(a) Reconstructed Taux (ECHAM)

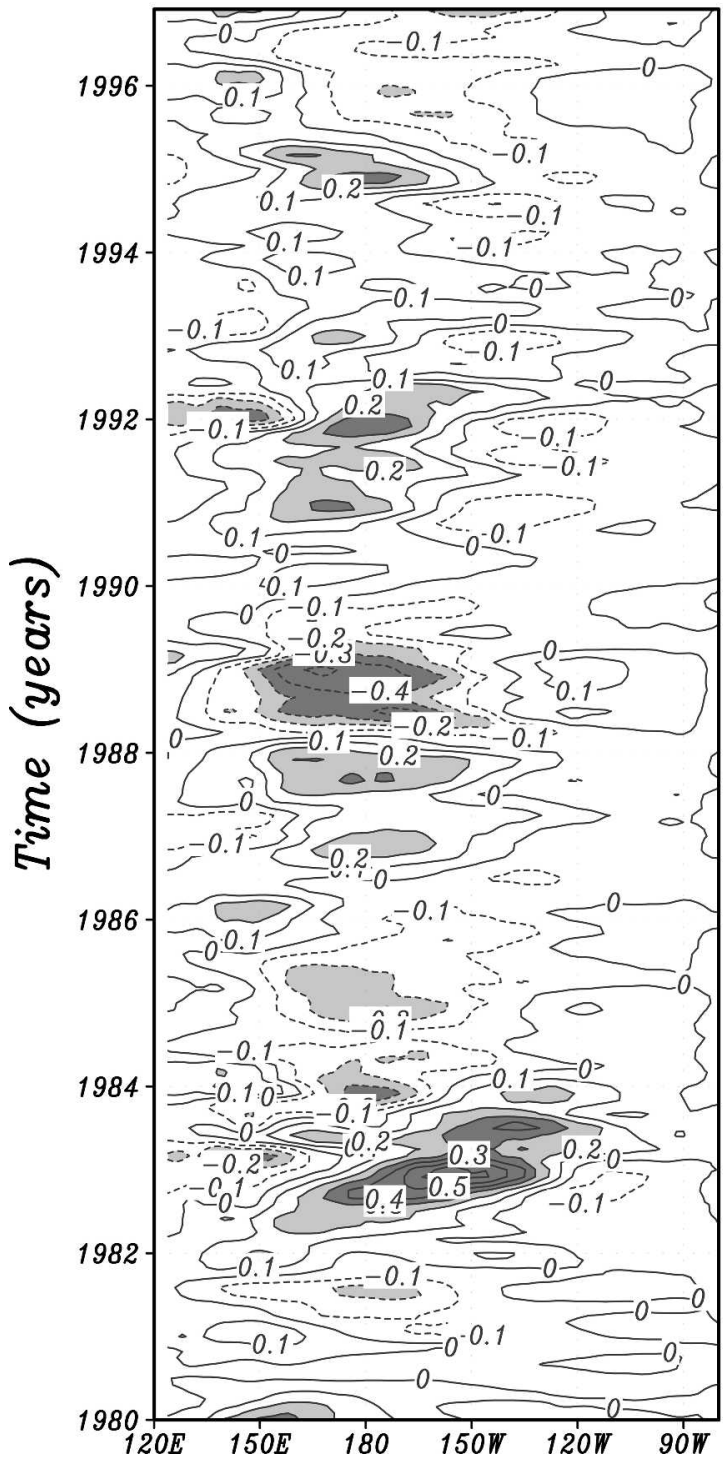

(b) SST from EOF-based Te model

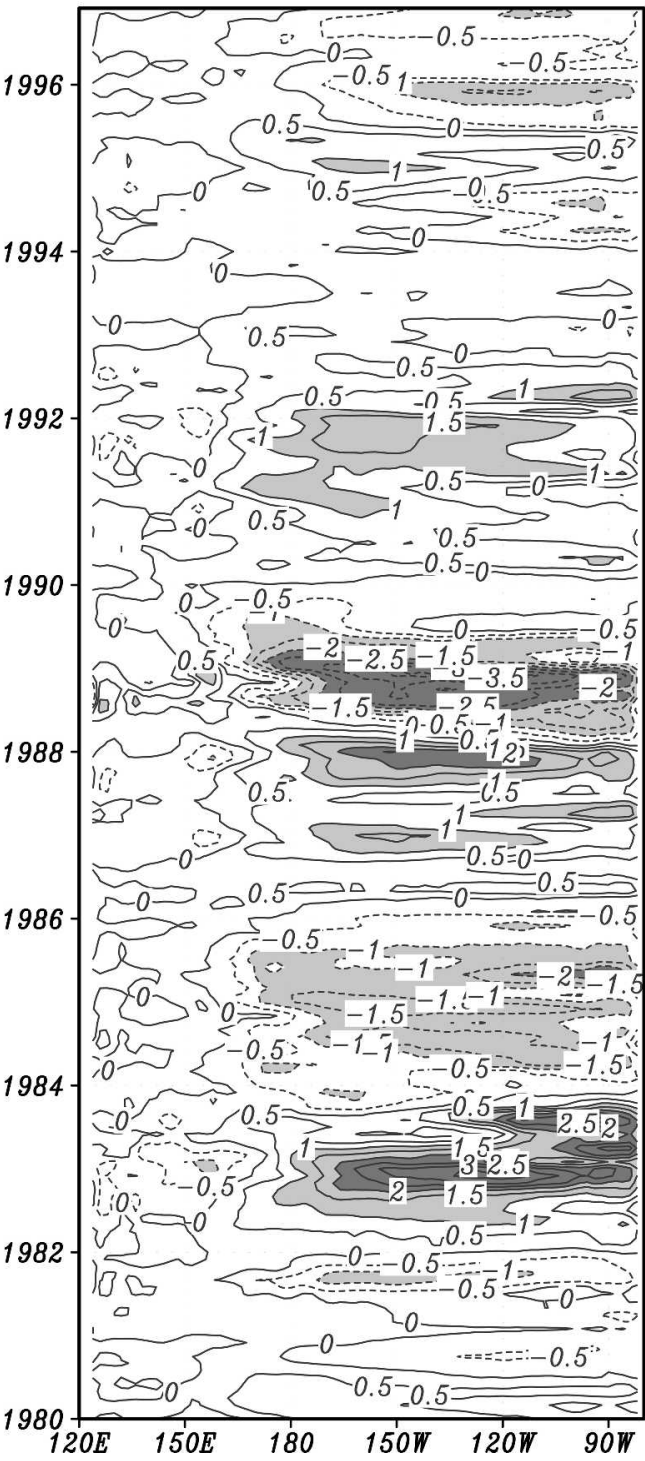

FIG. 6. (a) Zonal wind stress anomalies along the equator reconstructed via an empirical $\tau$ model from observed SST anomalies (Reynolds et al. 2002); (b) SST anomalies along the equator simulated from the model forced by the reconstructed wind stress anomalies shown in (a). The contour interval is $0.1 \mathrm{dyn} \mathrm{cm}^{-2}$ in (a) and $0.5^{\circ} \mathrm{C}$ in (b), respectively.

NCAR simulations (Fig. 5) but using current anomaly fields from the dynamical ocean model that is forced by wind stress anomalies constructed from the ECHAM4.5-based $\tau$ model (Fig. 6a). Note that the different wind stress fields are independently used to construct the empirical $T_{e}$ model and to force the dynamical ocean model. In this way, the performance of the empirical $\tau$ and $T_{e}$ models can be collectively evaluated in terms of SST anomaly simulations. The space-time evolution of the simulated SST interannual variability along the equator (Fig. 6b) is in good agreement with the corresponding observations (Fig. 3a), including the eastward migration of warm anomalies during El Niño events from the western Pacific (e.g., 1982/83 El Niño) and the westward spread of cold anomalies during La Niña events from the eastern basin (e.g., 1988/89 La Niña). The quality of the SST anomaly simulation demonstrates that there is little inconsistency between current/SSH and $T_{e}$ anomalies that may have been introduced by constructing the two empirical models from different wind data. The lack of imbalances in the SST anomaly simulation provides the basis for a simple 


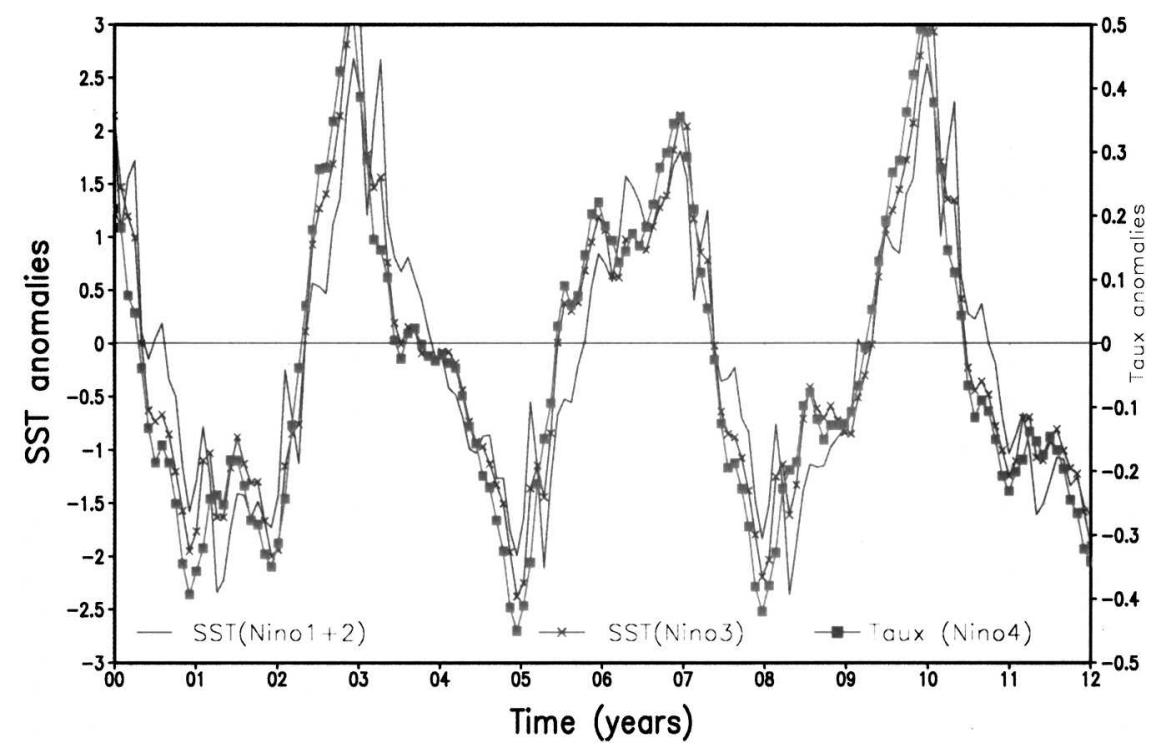

FIG. 7. Monthly time series of simulated SST anomalies from the coupled model for the Niño-1 +2 and Niño-3 regions $\left({ }^{\circ} \mathrm{C}\right.$; scales at left), and zonal wind stress anomalies for the Niño-4 region $\left(\right.$ dyn $\mathrm{cm}^{-2}$; scale at right), respectively.

hindcast/forecast initialization technique (described below).

\section{c. Coupled interannual variability}

The coupled system is initiated with an imposed westerly wind anomaly for 4 months, as in ZC87. Evolution of anomalies thereafter is determined solely by coupled interaction in the system. Time series of simulated Niño-1 + 2 and Niño-3 averaged SST anomalies, and Niño-4 averaged zonal wind stress anomalies indicate that the variability has reasonable spatial and temporal structure as well as realistic oscillation periods (Fig. 7). The most striking feature is that the system has a pronounced interannual oscillation with a dominant 3-4-yr period, with warm and cold SST anomalies that can be sustained for up to $1 \mathrm{yr}$ over the eastern and central basin, similar to observations. No clear phase lag can be clearly seen in the SST variations at these two sites, indicating a predominant standing pattern. In addition, the model reproduces the phase locking of interannual variability to the annual cycle very well: The largest eastern equatorial SST variability associated with El Niño and La Niña events always occurs near the end of the calendar year.

The longitude-time sections of anomalous SST and zonal wind stress along the equator (Fig. 8) show that the overall time scale, variability structure, and coherent phase relationships among these anomalies are consistent with the corresponding observations (e.g., Zhang and Levitus 1997). SST anomalies from this coupled model (Fig. 8a) have reasonable structure and amplitude both over the central and eastern equatorial Pacific, with a dominant standing pattern on the equator. A clear phase relationship between SST and zonal wind stress anomalies can be seen: SST and surface wind variations are nearly in phase temporally, but have phase differences in space. While fluctuations in SST are largest in the central and eastern equatorial Pacific, those in surface winds are dominantly located over the western and central equatorial regions. During the development of El Niño and La Niña events, zonal wind anomalies show an eastward migration from the western Pacific into the central basin, a feature that has been observed in nature (e.g., Zhang and Levitus 1997). At the height of El Niño, large warm SST anomalies $\left(\sim 2^{\circ} \mathrm{C}\right)$ cover the whole central and eastern basin, with westerly wind anomalies being located just west of the date line.

In addition, the model simulation appears to have other modes of variability, including decadal signals with double pulses (e.g., during years 01 and 02 , and during years 06 and 07, respectively). Variations in zonal wind stress also show a biennial oscillation in the far western Pacific. Detailed analyses of these variability modes and the effects of the empirical $\tau$ and $T_{e}$ models constructed on coupled variability will be addressed elsewhere.

\section{Initialization of the coupled prediction}

The success of a coupled model in predicting SST anomalies depends on many factors, including the per- 

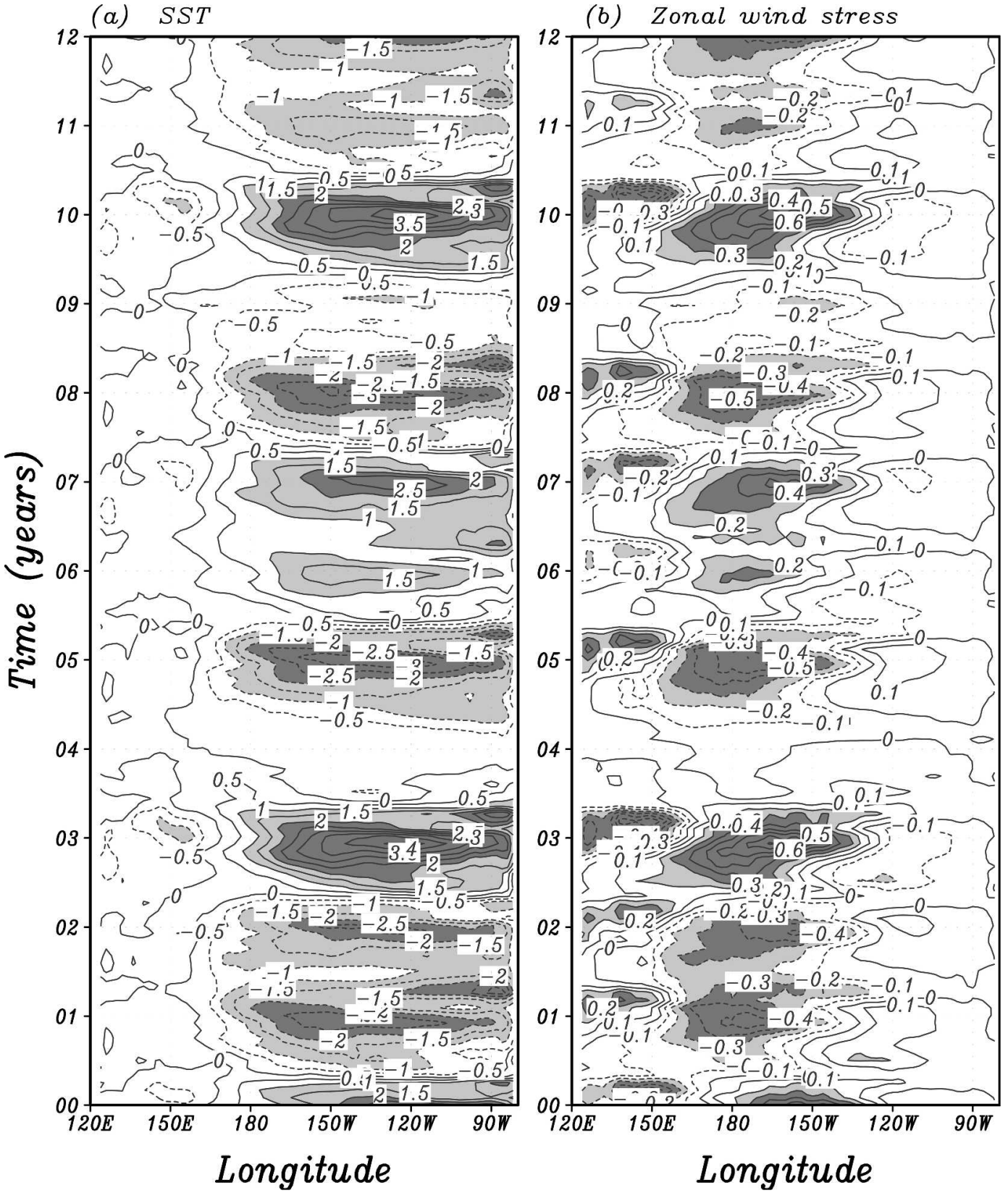

FIG. 8. Coupled interannual variability of (a) simulated SST and (b) zonal wind stress anomalies along the equator. The contour interval is $0.5^{\circ} \mathrm{C}$ in (a) and $0.1 \mathrm{dyn} \mathrm{cm}^{-2}$ in (b), respectively.

formance of each component model, initial ocean conditions, and their consistency at the start time. In particular, coupled initialization is essential to suppress initial shock associated with mismatch between model and forcing fields at the start time of predictions. (An additional shock will also occur when the model's mean climate differs from the observed.) To address these problems, a variety of initialization schemes have been developed. Here, a simple initialization procedure is adopted that makes direct use of SST observations (e.g., Barnett et al. 1993), since these data are of superior quality.

The initialization scheme, which makes use of observed SST anomalies, is as follows. Wind stress anomalies, as have been shown in Fig. 6a, are first constructed from observed SST anomalies (Fig. 3a) via the SVDbased $\tau$ model for a period covering the hindcast period (January 1963-December 2002). These reconstructed wind stress anomalies are then used to integrate the ocean model over the whole hindcast period (or for a 

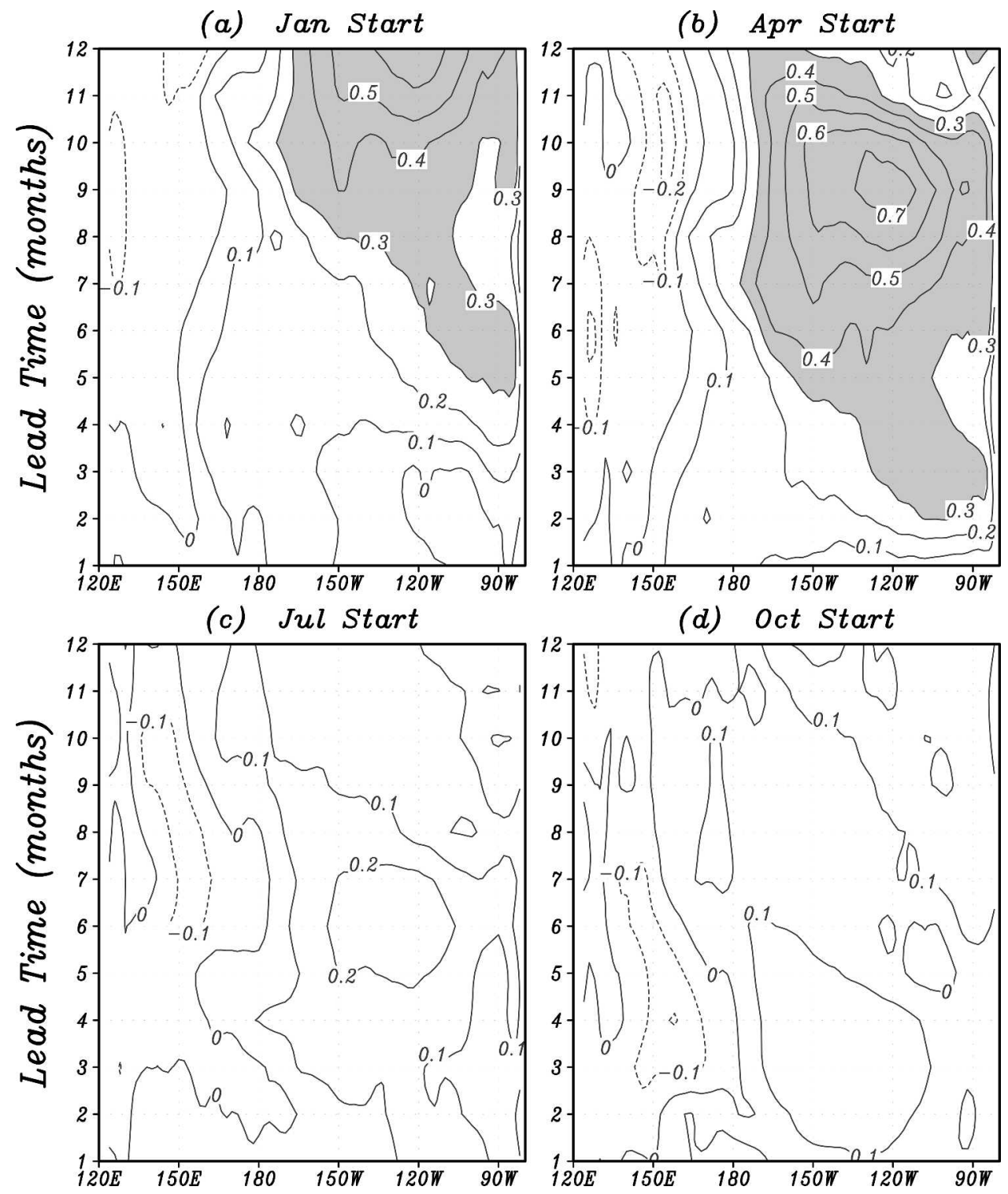

(d) Oct Start

FIG. 9. Systematic errors of predicted SST anomalies along the equator from the coupled model, as a function of lead times from (a) Jan start, (b) Apr start, (c) Jul start, and (d) Oct start, respectively. This is obtained by averaging all SST predictions starting from the same months of all years and having the same lead times during the period $1963-97$. The contour interval is $0.2^{\circ} \mathrm{C}$.

forecast, up to the beginning of prediction time) to generate initial conditions for the dynamical component. The SST anomaly model initial conditions are taken as the observed SST anomalies (i.e., observed SST anomaly fields from the previous month are simply "injected" into the model at each start time, the first of each month).

\section{SST anomaly hindcast results}

Predictions have been made starting from each month during the period 1963-2002, each extending out to 12 months, using the simple initialization procedure described above. During the prediction period, the evolution of the model states is determined solely by coupled air-sea interactions in the tropical Pacific Ocean. In this section, hindcast results are presented for the period 1963-97, yielding a total of 420 hindcasts, 35 members for each calendar month. To examine the ability of the ICM to predict changes in the equatorial Pacific SST, simple anomaly correlations and rootmean-square (rms) errors are calculated between model-predicted and observed SST anomalies. Skill estimates are computed as a function of lead time, initial 
(a) Lead times: 3 months

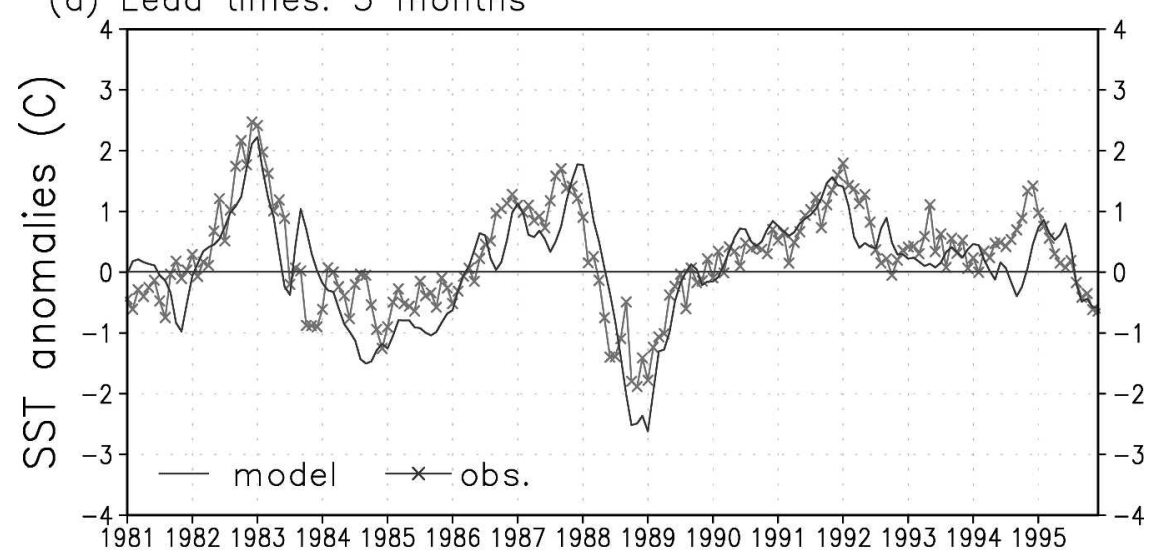

(b) Lead times: 6 months
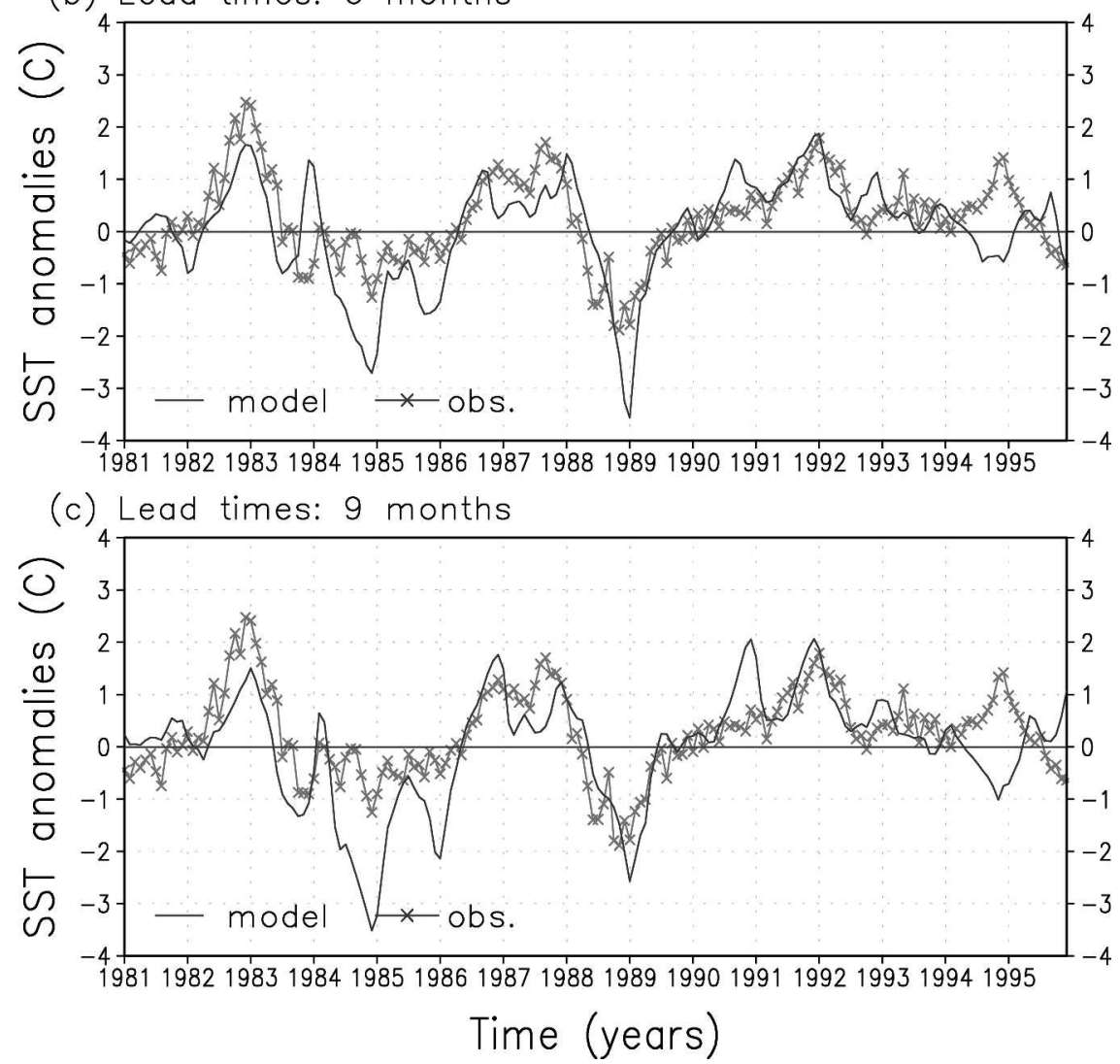

FIG. 10. Examples of the predicted and observed Niño-3.4 SST anomalies during the period 1981-95 for 3-, 6-, and 9-month lead times, respectively.

calendar month, and geographic locations. The significance of the correlation coefficients is estimated using a Student's $t$ test.

Note that, in this section, the $T_{e}$ and $\tau$ models that are trained during the period 1963-96 are used. As such, the skill for SST predictions can be artificial, because of observational information of SST and $\tau$ variability covering the prediction period being already included in the training period. Also, note that the relative coupling coefficient and thermocline coefficient are ad hoc tuning parameters and their choices are based on the model performance of coupled SST variability (i.e., the amplitude and structure; shown in Fig. 8a). The current choice of these parameters may represent the best results in terms of SST prediction skill and thus may have introduced artificial skill. Further retrospective forecast 

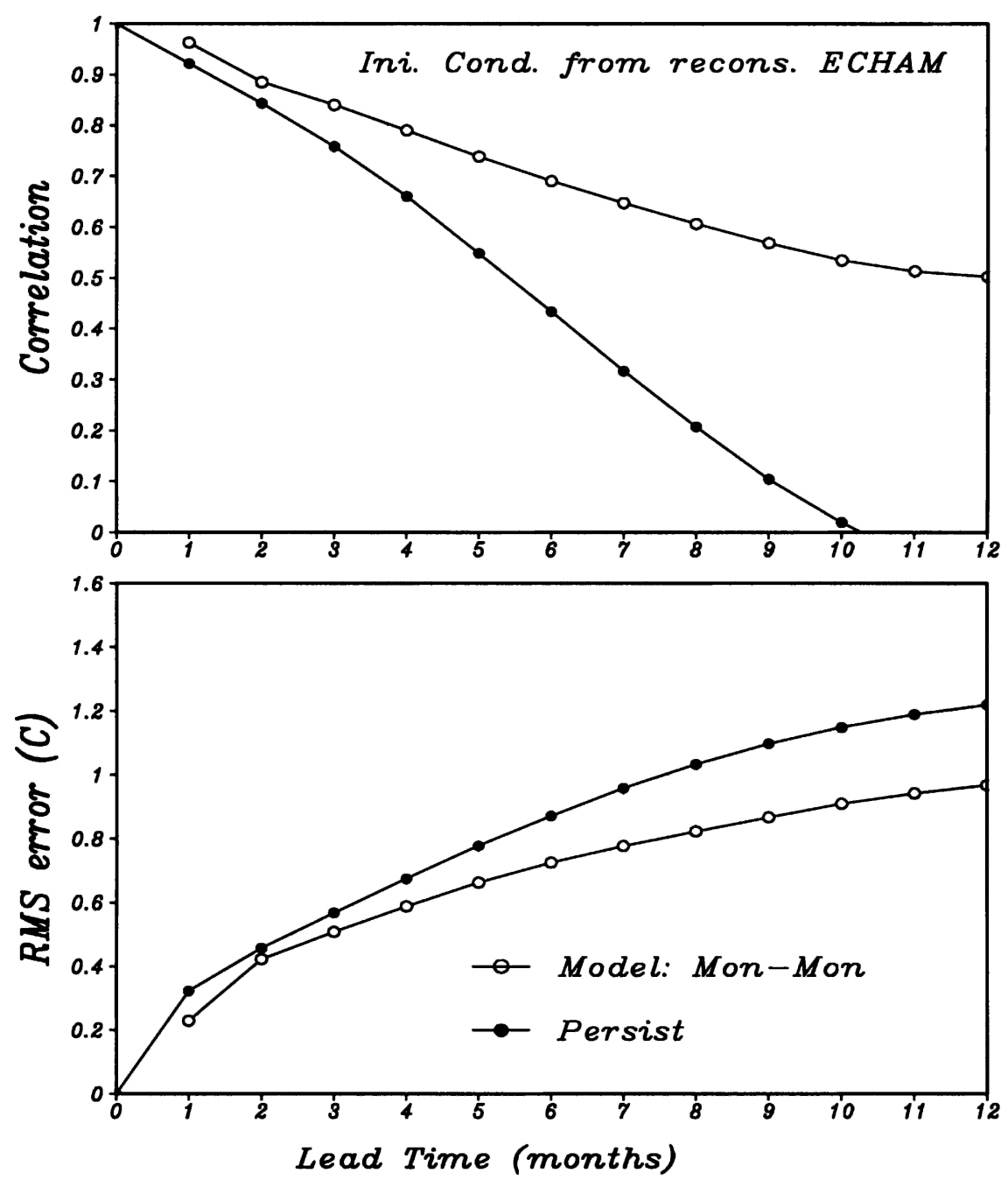

FIG. 11. (top) Anomaly correlations and (bottom) rms errors of the Niño-3.4 SST anomalies for the model prediction (solid lines with open circle) and for persistence (solid lines with closed circle) shown as a function of lead times. The results are obtained for all predictions made during the period 1963-97 regardless of their starting month (420 ensemble members).

experiments are needed to examine the sensitivity of the SST prediction skill to these parameters.

\section{a. Systematic errors}

In ocean GCM-based prediction systems, climate drift is still a significant problem, with large systematic model biases (e.g., Schneider et al. 2003), which in some cases are much larger than the anomalies being predicted. Various practical methods are used to reduce or remove these systematic errors. Some coupled models employ flux corrections to reduce climate drift (e.g., Chen et al. 2000). In other models, carefully calculated systematic errors, which are functions of prediction start month and lead time, are subtracted from the predicted SST fields to provide a bias corrected forecast (e.g., Stockdale et al. 1998). Finally, model output statistics (MOS) corrections are sometimes performed to enhance prediction skill (e.g., Barnett et al. 1993).

Figure 9 shows systematic errors in predicted SST anomalies from the ICM, which are defined as the mean of all SST anomaly predictions for the period 1963-97 and calculated as a function of initial calendar month. Along the equator, there is a warming trend in the central and eastern basin, and a cooling trend to the west (e.g., Fig. 9b). Largest errors (less than $0.8^{\circ} \mathrm{C}$ ) occur in December with predictions started from January and April (Figs. 9a,b, respectively). As compared to other coupled models that have been documented in the literature (e.g., Chen et al. 2000; Schneider et al. 2003), systematic errors of predicted SST anomalies 
(a) Lead time: O Month

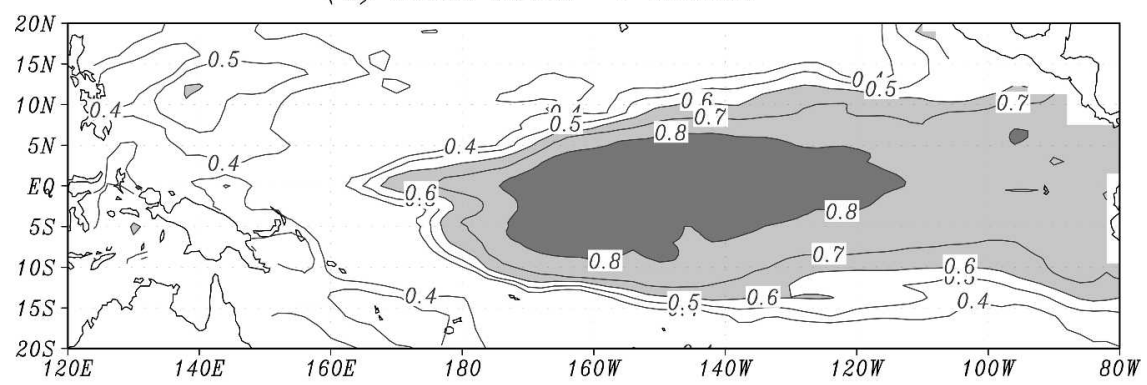

(b) Lead time: 3 Months

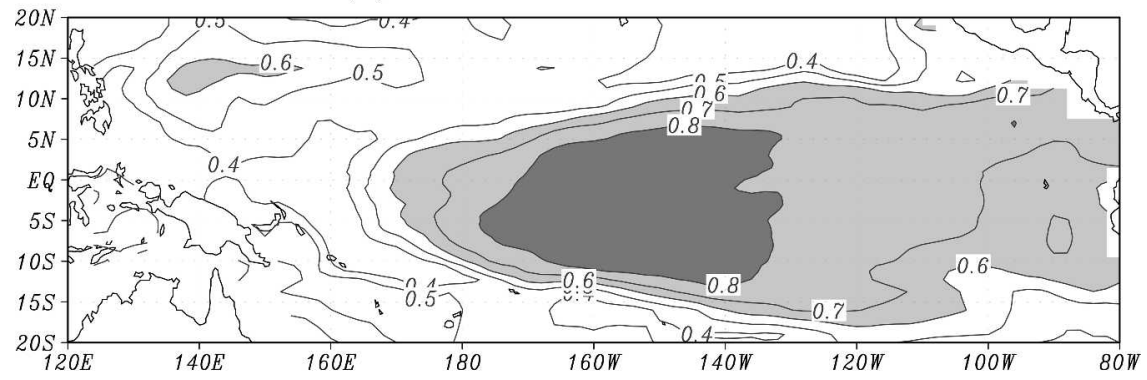

(c) Lead time: 6 Months

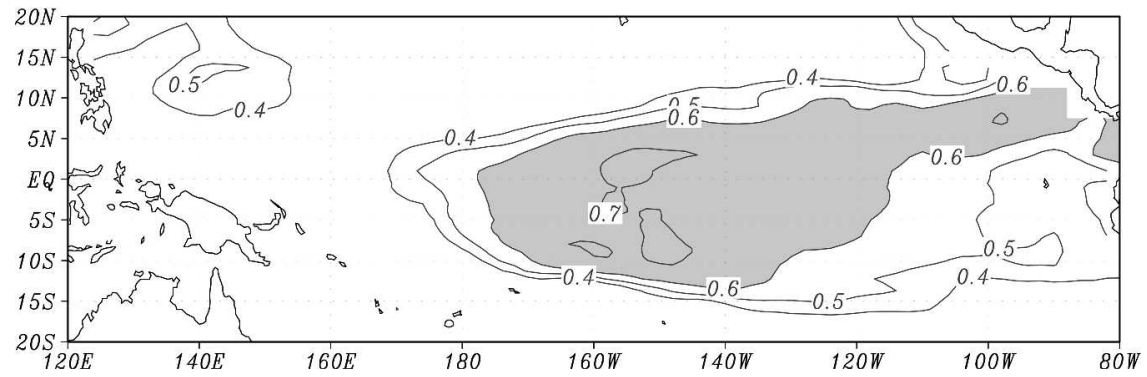

FIG. 12. Horizontal distributions of anomaly correlations between observed and predicted SST anomalies at 0-, 3-, and 6-month lead times, respectively. The results are obtained for all predictions made during the period 1963-97 regardless of prediction starting month (420 ensemble members). The contour interval is 0.1 .

from this coupled system are significantly smallerapparently due to the improved empirical $T_{e}$ parameterization. It is quite clear that climate drift in this model is not a concern.

Since the systematic biases in SST anomaly predictions are small from the coupled model that directly produces interannual anomalies, we have not performed any postprocessing procedure to enhance the skill for SST anomaly prediction. So, the results shown in this paper below are directly from the model output, with no additional corrections applied.

\section{b. Predicted SST anomalies}

Figure 10 shows examples of predicted and observed Niño-3.4 SST anomalies at 3-, 6-, and 9-month lead times. No systematic bias is evident in SST anomaly prediction, nor can initial shock be seen at the initial stage of prediction. The predicted SST anomalies closely follow the corresponding observations, although at longer lead times cold SST anomalies produced are slightly stronger in 1984/85 and in 1988/89. The model captures the onset and developments of major warm and cold events, and their transition, quite well. In particular, a phase delay of predicted SST anomalies relative to observations, a common feature to some hybrid coupled models (e.g., Syu and Neelin 2000), is not evident in this coupled system. However, high-frequency fluctuations observed in nature are not well represented in the coupled model; the predicted SST anomalies are instead quite smooth. In addition, there are few false alarms.

\section{c. Mean prediction skill}

The skill estimates in this section are based on the full hindcast period, 1963-97, a total of 420 members. 
(a) Lead time: O Month

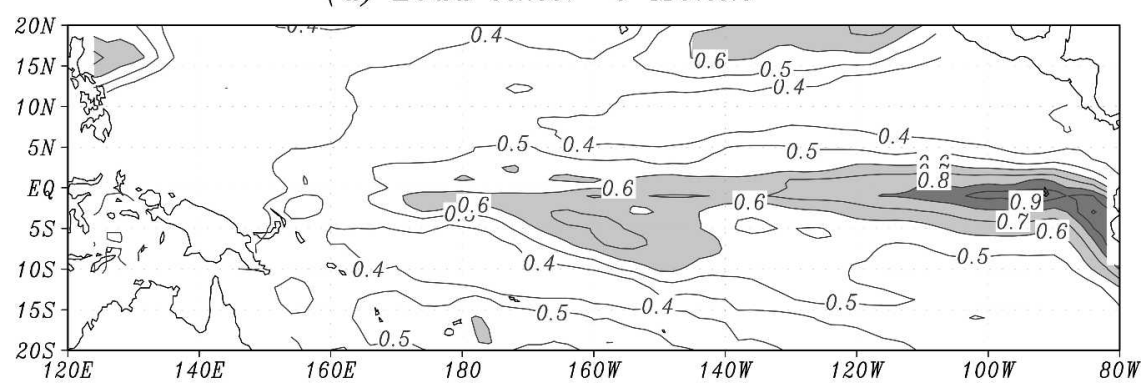

(b) Lead time: 3 Months

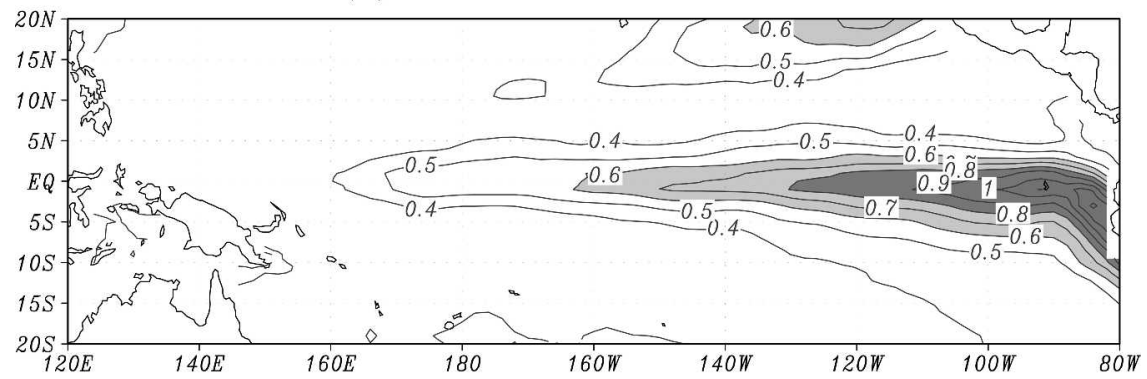

(c) Lead time: 6 Months

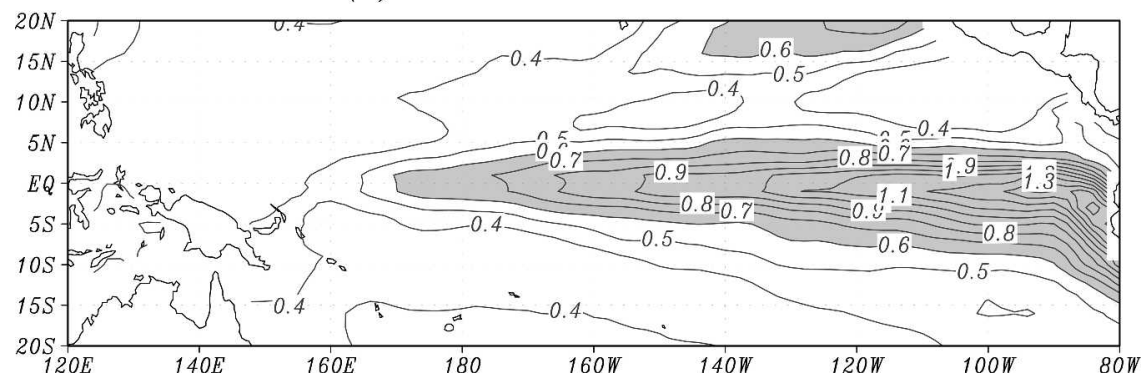

FIG. 13. Same as in Fig. 12 but for rms errors.

Anomaly correlation and rms errors between observed and predicted Niño-3.4 averaged SST anomalies as a function of lead times are shown in Fig. 11. The correlation coefficient is at the $95 \%$ confidence level if it is greater than 0.11 according to a Student's $t$ test. The model has particularly high skill at short lead times, with a correlation of 0.97 for the first month and remaining above 0.8 out to 4 -month lead time. As a result, the model skill beats persistence at all lead times in the central equatorial Pacific. This is no doubt due to the well-balanced model setup, which allows observed SST anomalies to be used in the coupled initialization technique with minimal coupling shock. The better performance over the persistence indicates that the model is able to sustain the observed SST information well in the coupled system. Beyond 4-month lead time, there is a steady decrease in skill but the correlation remains greater than 0.5 up to a lead time of 12 months, with the rms errors remaining smaller than $1^{\circ} \mathrm{C}$ over the 12 month prediction period.
Figures 12 and 13 display the horizontal distribution of the anomaly correlations and rms errors at lead times of 0,3 , and 6 months, respectively. Results at month- 0 lead time, whose SST anomalies along the equator have been shown in Fig. 6b, present model skills in the forced simulation by the reconstructed wind anomalies (Fig. 6a) via the ECHAM4.5-based $\tau$ model from the observed SST anomalies (Fig. 3a). A V-shaped pattern of correlation is evident: high value regions are located in the central and eastern equatorial Pacific, flanked by two low bands in northwestern and southwestern sides off the equator, and another relatively high region in the far western Pacific. At 0-month lead time (Fig. 12a), the correlation is over 0.8 in the central basin and over 0.7 in the eastern basin. At 3-month lead time (Fig. 12b), the skill does not drop much in the central basin and has only a small decrease in the eastern basin; the correlation remains greater than 0.8 in the central basin and the rms error less than $1^{\circ} \mathrm{C}$ over the entire region (Fig. 13). Geographically, this model performs consid- 


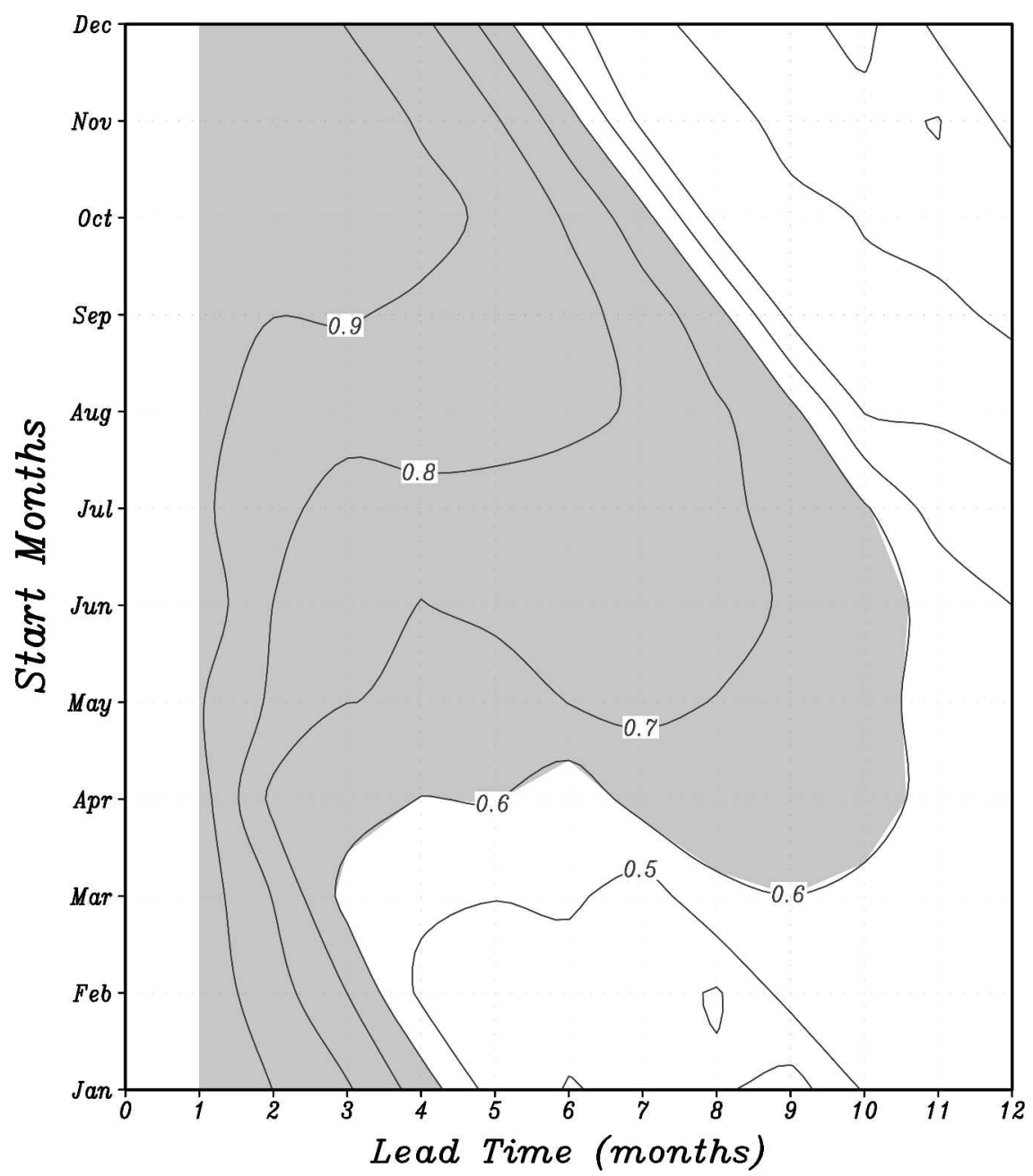

FIG. 14. Anomaly correlations of the Niño-3.4 SST anomalies during the period 1963-97, as a function of lead time and start month. The contour interval is 0.1 .

erably better in the central equatorial Pacific than in the eastern basin. With the increase in lead time, the correlation drops first and fastest in the eastern basin than in the central basin. At 6-month lead time (Figs. $12 \mathrm{c}$ and $13 \mathrm{c}$ ), correlation skill larger than 0.6 is found over a sizable region of the central Pacific, but east of $110^{\circ} \mathrm{W}$, it drops below 0.5 , with largest error being located in the eastern equatorial and coastal region of North America. Compared to persistence (e.g., see Ji et al. 1996; Schneider et al. 2003), the model has better skill at all lead times in most regions.

\section{d. Seasonality of the skill}

To examine the seasonality of skill, correlations are calculated as a function of initiation month and lead time for the period 1963-97 (a total of 35 members for each correlation). Such an analysis for the Niño-3.4 region is shown in Fig. 14. A striking feature is that the prediction skill of SST anomalies is highly dependent on the seasons, similar to previous results (e.g., Chen et al. 1995; Schneider et al. 2003), and depends sensitively on the initiation month. Correlation skill is relatively low for predictions starting in the earlier part of the year before April, and significantly higher for predictions starting thereafter. The boreal spring predictability barrier is also evident: the most rapid decrease of skill occurs as the hindcasts pass through the (northern) spring. The single most rapid drop in skill occurs for hindcasts started in April and occurs in the first month. Whereas for hindcasts starting between July to October, skill is maintained significantly higher-starting around 0.98 and remaining above 0.7 up to a lead time of 6 months. A partial recovery in skill is also seen after passing the spring predictability barrier.

More details of the seasonal dependence are shown in Fig. 15 for the correlations along the equator as a 
(a) Jan Start

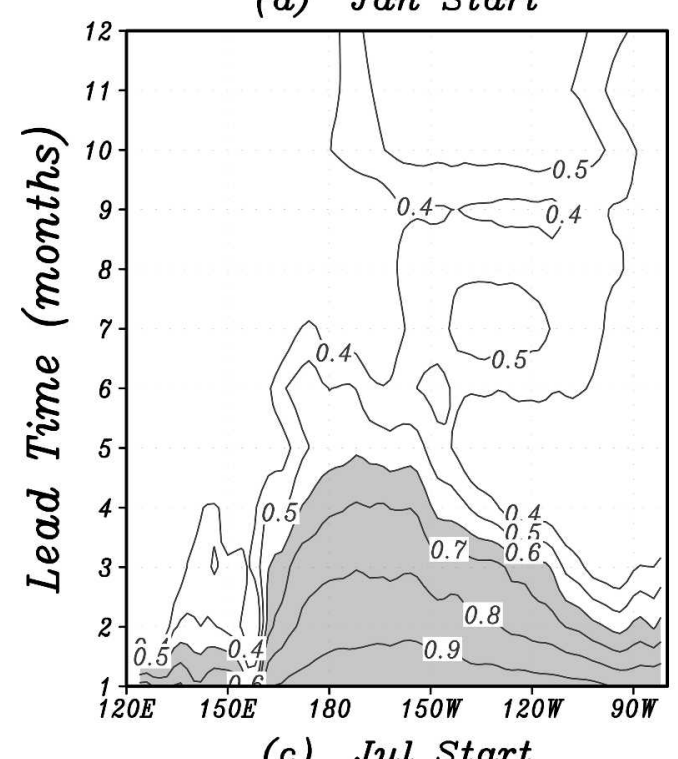

(c) Jul Start

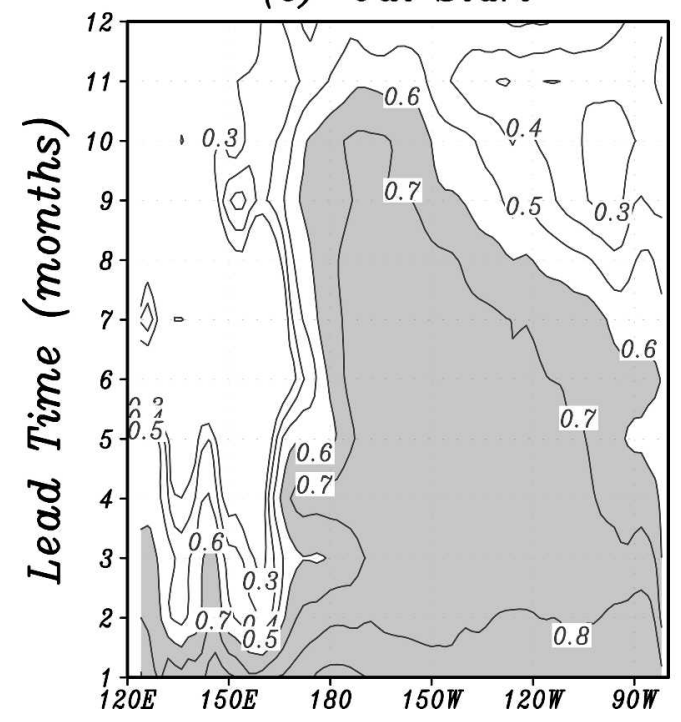

(b) Apr Start

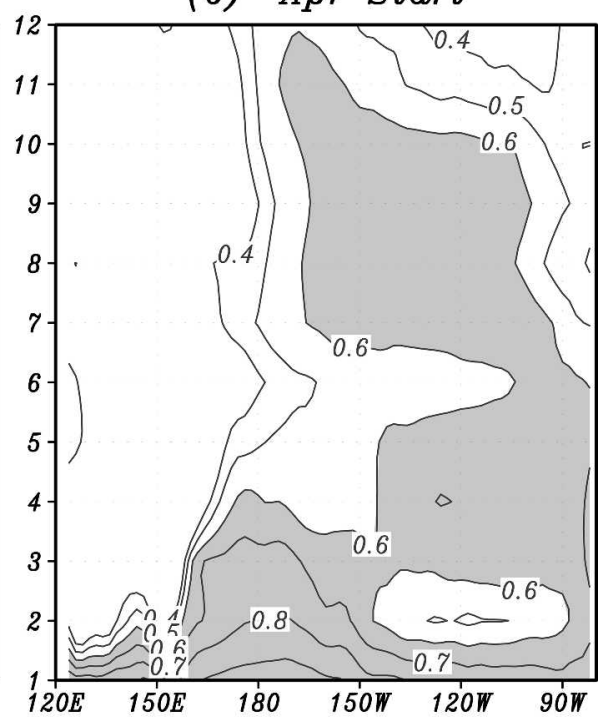

(d) Oct Start

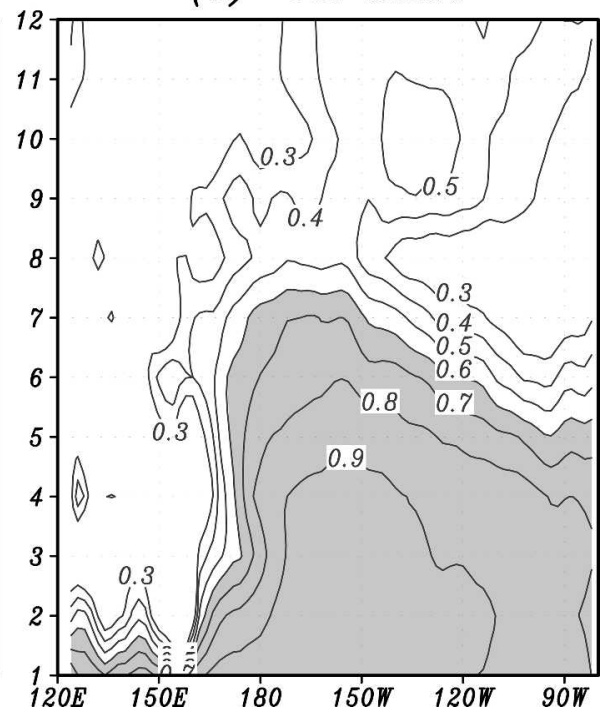

FIG. 15. Anomaly correlations between observed and predicted SST anomalies along the equator during the period 1963-97, as a function of lead times starting from (a) Jan, (b) Apr, (c) Jul, and (d) Oct initial conditions, respectively. The contour interval is $0.1^{\circ}$.

function of lead time at different start months. There is a quick decrease in the skill for predictions starting early in year. For hindcasts starting in January, skill drops very fast with lead time across the entire equatorial basin, while for starts between July and October, there is a slow decrease along the equator, with the correlation remaining great than 0.8 in the central basin until the next spring. Geographically, the correlation drop begins in the eastern equatorial Pacific and tends to spread westward along the equator.

It is obvious that the model performs best in the central equatorial Pacific, and less well in the eastern equatorial Pacific, where the skill is relatively low and drops much faster with lead time. At short lead time, the skill clearly outperforms the Lamont-Doherty Earth Observatory model (LDEO4; e.g., Chen et al. 2000); at longer lead time (9 to 12 months) the skill is lower than the LDEO4 in the eastern basin. In addition, the spring barrier in forecast skill is particularly strong in this coupled system.

\section{Cross-validation studies}

The EOF-based empirical $T_{e}$ model developed here is empirical in nature. As with any statistical method, its 
Lead time: 3 months

(a) Dependent case: Te (1963-96) $\Rightarrow$ 1963-79

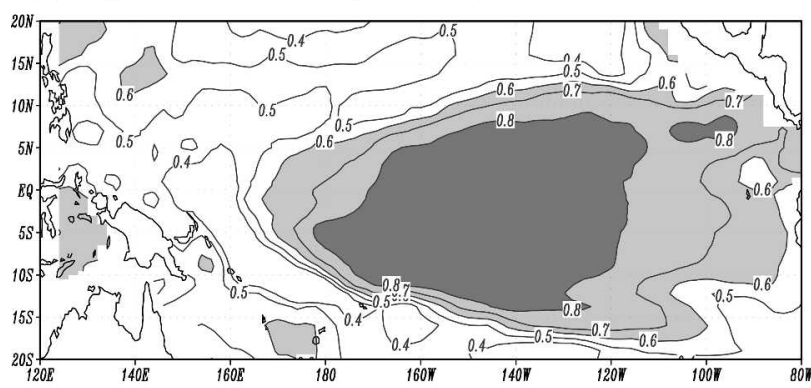

(b) Dependent case: Te (1963-79) $\Rightarrow$ 1963-79

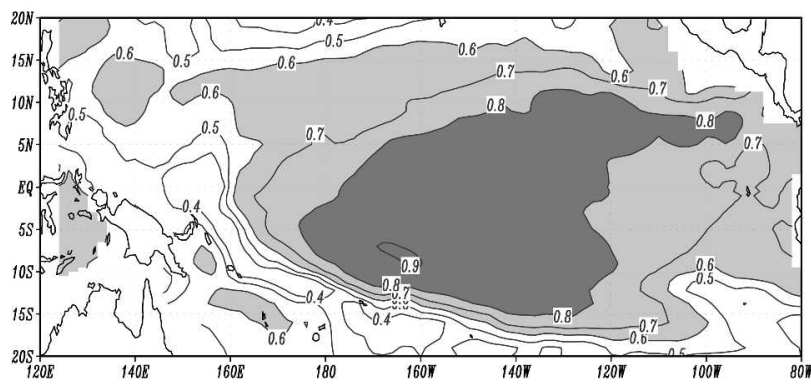

(c) Independent case: Te (1980-96) $\Rightarrow$ 1963-79

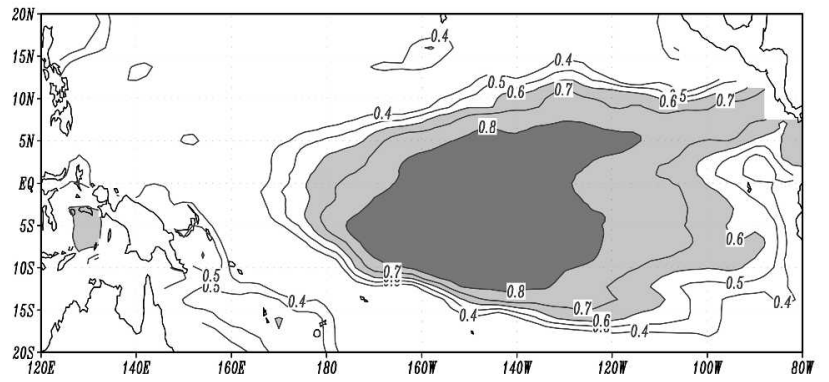

Lead time: 6 months

(d) Dependent case: Te (1963-96) $\Rightarrow$ 1963-79

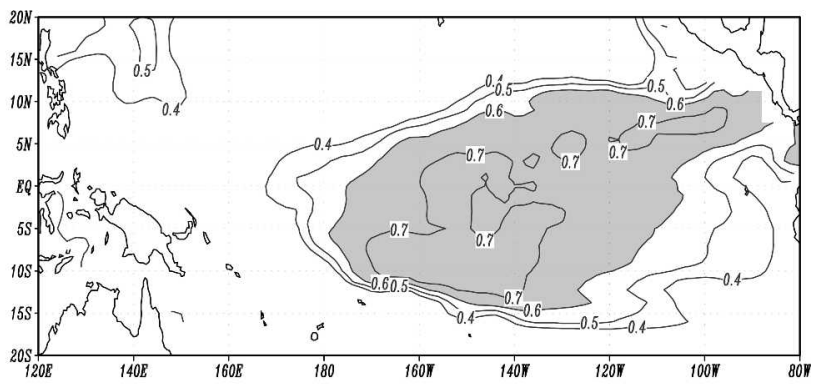

(e) Dependent case: Te (1963-79) $\Rightarrow$ 1963-79

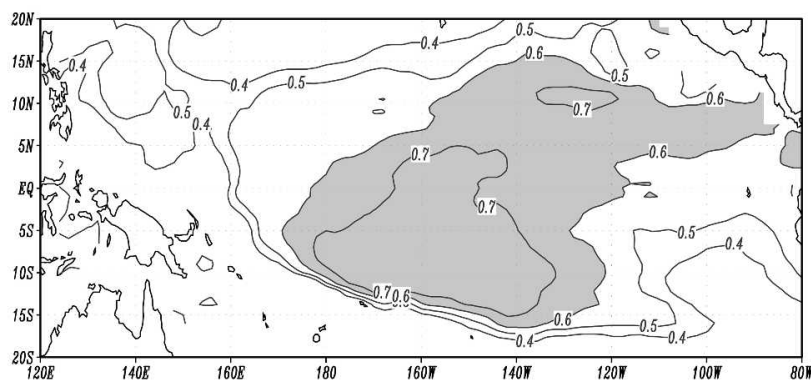

(f) Independent case: Te (1980-96) $\Rightarrow$ 1963-79

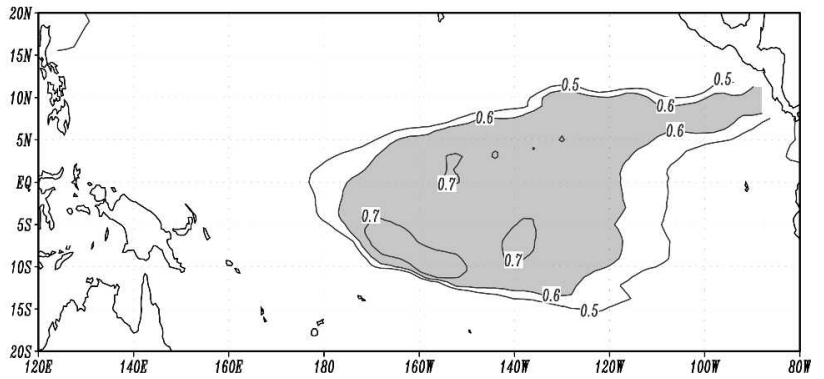

FIG. 16. Horizontal distributions of anomaly correlations between observed and predicted SST anomalies during the period 1963-79 (the prediction period) at (left) 3-month and (right) 6-month lead times, via the EOF-based $T_{e}$ models that are constructed from the same or overlapping periods (dependent cases) or from different period (independent cases), respectively. The contour interval is 0.1 .

performance in simulation and prediction depends on several factors, including the data period selected for estimating the $\mathrm{SSH}-T_{e}$ relation (the training period), which is then used to predict SST anomalies (the prediction period). If the training period overlaps the prediction period, the SST prediction skill may be partly artificial, since observations (SST) have already been included in both the inverse estimation of $T_{e}$ and the $\mathrm{SSH}-T_{e}$ regression analysis. In this section, sensitivity experiments are presented to assess the artificial skill contribution. Note that in this paper, we are focusing on the $T_{e}$ effects on SST prediction, and the cross validation is only applied to the empirical $T_{e}$ model of the coupled system (Fig. 1). Further experiments are needed to perform the cross validation for both the empirical $\mathrm{T}_{\mathrm{e}}$ and $\tau$ models simultaneously.
Hindcasts are performed with two additional $T_{e}$ models, constructed for the periods 1963-79 and 1980-96, respectively. The experiments are termed dependent (independent) cases when the prediction and training periods overlap (do not overlap). Figures 16 and 17 show the correlations between predicted and observed SST anomalies separately calculated for the two periods 1963-79 and 1980-97, respectively. Results with the $T_{e}$ model constructed from the entire period 1963-96 are also shown for reference. As expected, the SST anomaly correlation values for the dependent cases (Figs. 16a,b,d,e and 17a,b,d,e) are higher than those for the independent cases (Fig. 16c, 16f, 17c, and 17f). However, the differences in general are not large. Over the central equatorial Pacific the drop in skill is not more than 0.1 at 3 - and 6-month lead time. In the east- 


\section{Lead time: 3 months}

(a) Dependent case: Te (1963-96) $\Rightarrow$ 1980-97

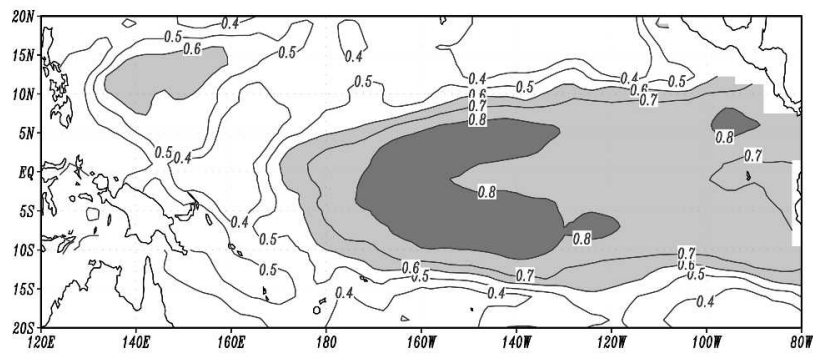

(b) Dependent case: Te (1980-96) $\Rightarrow$ 1980-97

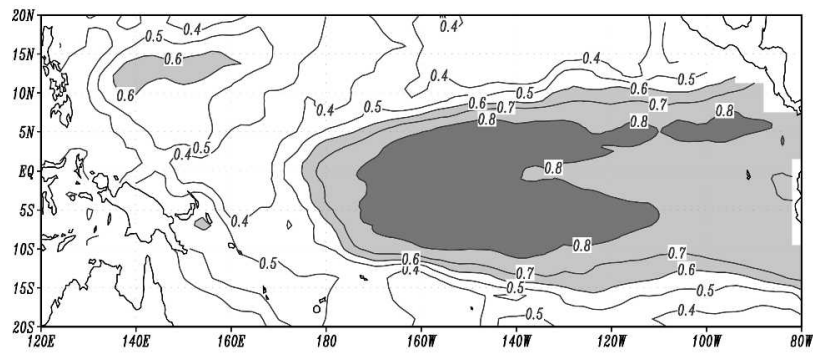

(c) Independent case: Te (1963-79) $\Rightarrow$ 1980-97

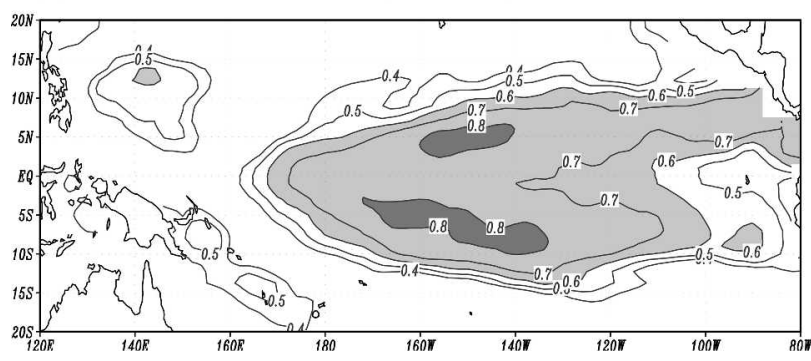

Lead time: 6 months

(d) Dependent case: Te (1963-96) => 1980-97

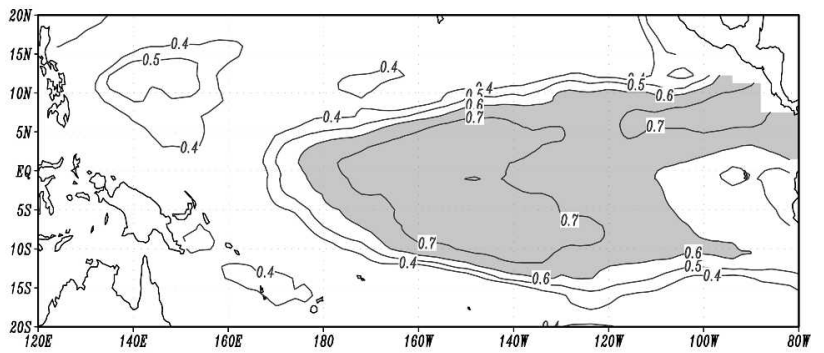

(e) Dependent case: Te (1980-96) => 1980-97

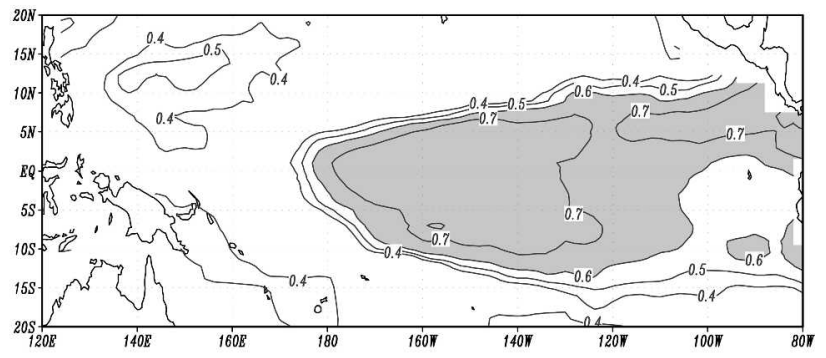

(f) Independent case: Te (1963-79) $\Rightarrow$ 1980-97

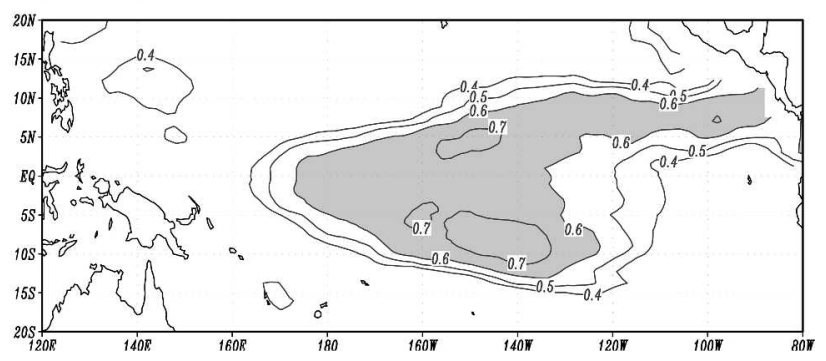

FIG. 17. Same as in Fig. 16 but for the period 1980-97.

ern equatorial Pacific the drop in skill is somewhat larger. Thus, the artificial increase in skill due to using a dependent $T_{e}$ model is not large. Furthermore, the correlation obtained from the two independent cases is still quite high as compared with other model predictions (e.g., Schneider et al. 2003). In particular, correlation values over 0.6 cover a broad area in the central equatorial basin at 6-month lead time.

\section{Forecast experiments during the period 1997-2002}

Finally, we present some results from a forecast experiment for the period 1997-2002. Here, the two $\tau$ and $T_{e}$ empirical models are both constructed during the period 1963-96. Thus this experiment is a stricter test of model than above, since now the $\tau$ model is also independently trained. Furthermore, predicting the onset of the 1997/98 El Niño event from the late 1996 or early
1997 is still a challenge to many forecast models (e.g., Barnston et al. 1999). Figure 18 shows observed SST anomalies for longitude-time sections along the equator during the period 1997/98 and for horizontal distributions during the development of the 1997/98 El Niño event. The model prediction results are presented in Figs. 19 and 20.

The model successfully forecasts the 1997/98 El Niño event and the following cold event at 12-month lead time (Fig. 19a). The onset of the 1997/98 El Niño event is surprisingly well predicted from early 1997. The amplitude of the 1997/98 El Niño event is captured quite well, but the rapid warming in the late spring of 1997 is underestimated. There is a slight delay in peak time relative to observation, with a shorter duration of the warming in spring 1997. The model also predicts the turnabout into the La Niña event in early 1998 well, though the cooling takes place too early and too strongly. Figures $19 \mathrm{~b}$ and $19 \mathrm{c}$ demonstrate the evolu- 
(a) SSTAs along the equator

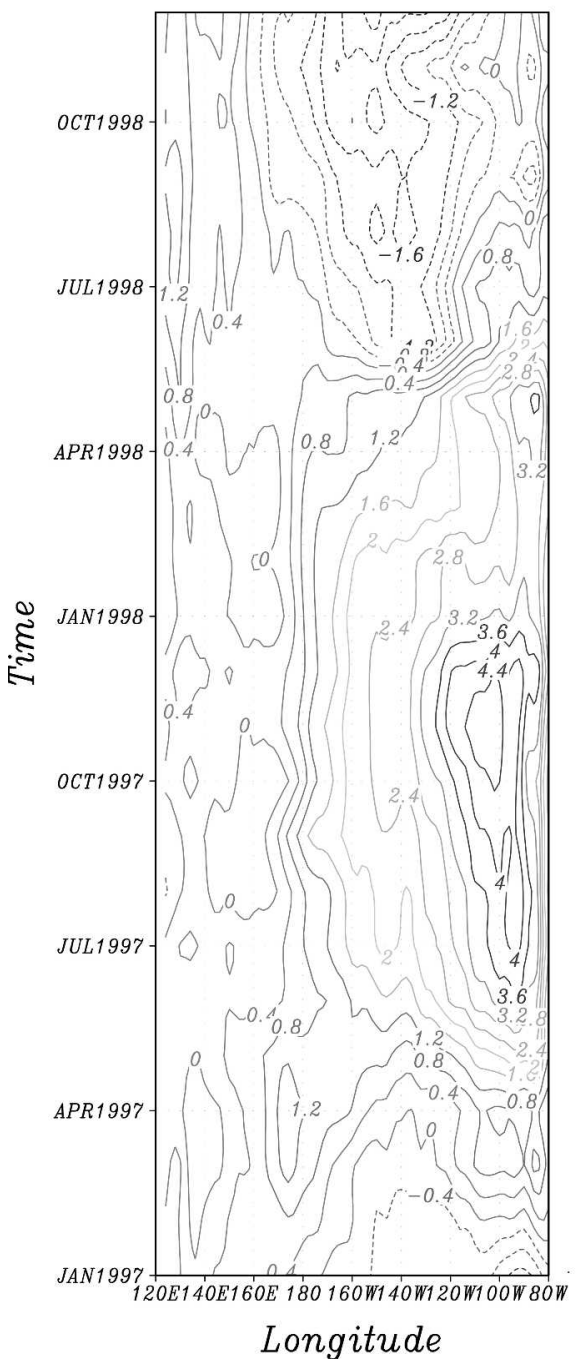

(b) June 1997

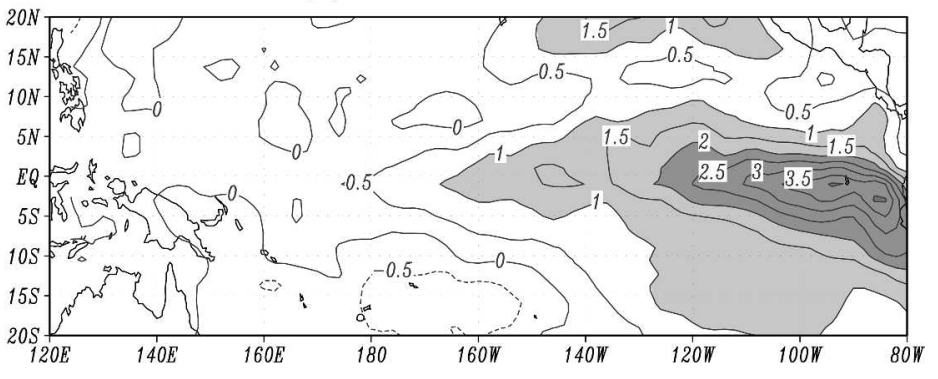

(c) $\operatorname{Sep} 1997$

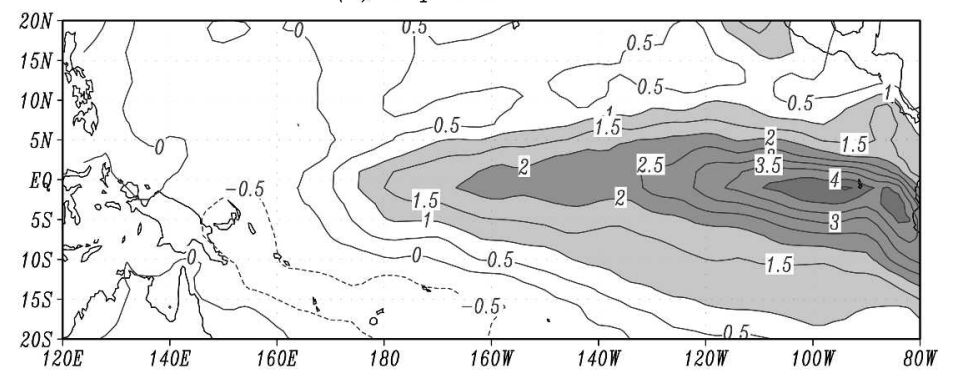

(d) Dec 1997

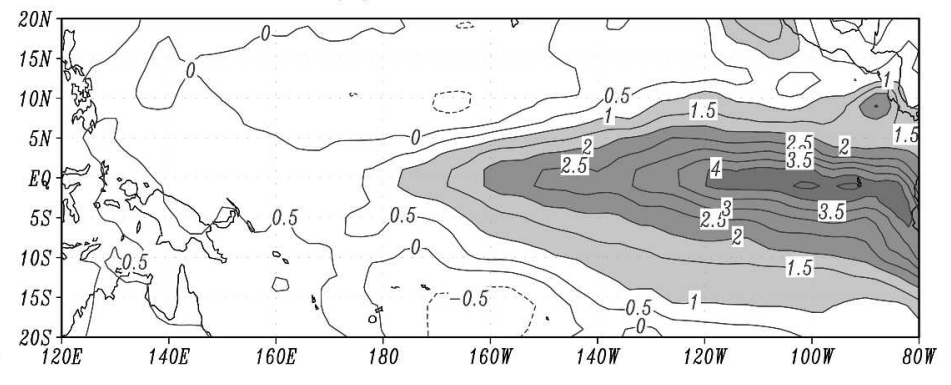

FIG. 18. Observed SST anomalies for longitude-time sections along the equator during the period (a) 1997/98, and for horizontal distributions in (b) Jun 1997, (c) Sep 1997, and (d) Dec 1997, respectively. The contour interval is $0.4^{\circ} \mathrm{C}$ in (a) and $0.5^{\circ} \mathrm{C}$ in (b)-(d).

tion of the predicted SST anomalies along the equator started from January 1997 and January 1998, respectively. As compared with the corresponding observations (Fig. 18a), the predicted SST variability along the equator for 1997 and 1998 has reasonable structure over the equatorial Pacific, although in the eastern equatorial Pacific the amplitude of the 1997/98 El Niño event is underestimated (Fig. 19b) and the cold anomalies are overestimated (Fig. 19c).

The spatial structure and evolution of predicted SST anomalies during the onset and development of the 1997/98 El Niño (Fig. 20) is in good agreement with the corresponding observations (Figs. 18b-d). The warming can be predicted one year in advance: the signal first appears over the western equatorial Pacific in early
1997 (Fig. 19b), followed by a warming in the eastern equatorial Pacific in May-June (Figs. 19b and 20a). During the summer and fall, the warming grows rapidly both in the central and eastern basins. By December 1997, warm anomalies cover the entire equatorial basin (Fig. 20c).

The correlation between predicted and observed SST anomalies is further shown in Fig. 21 for the period January 1997-December 2001. The prediction skill for this period is quite comparable with or even superior to that from other periods shown above (e.g., Figs. 12, 16, and 17). These results are very encouraging and clearly indicate that the prediction skill of the coupled system is not particularly dependent on the data periods selected for constructing the two empirical models. Al- 
(a) Nino 3 SSTA from different start months
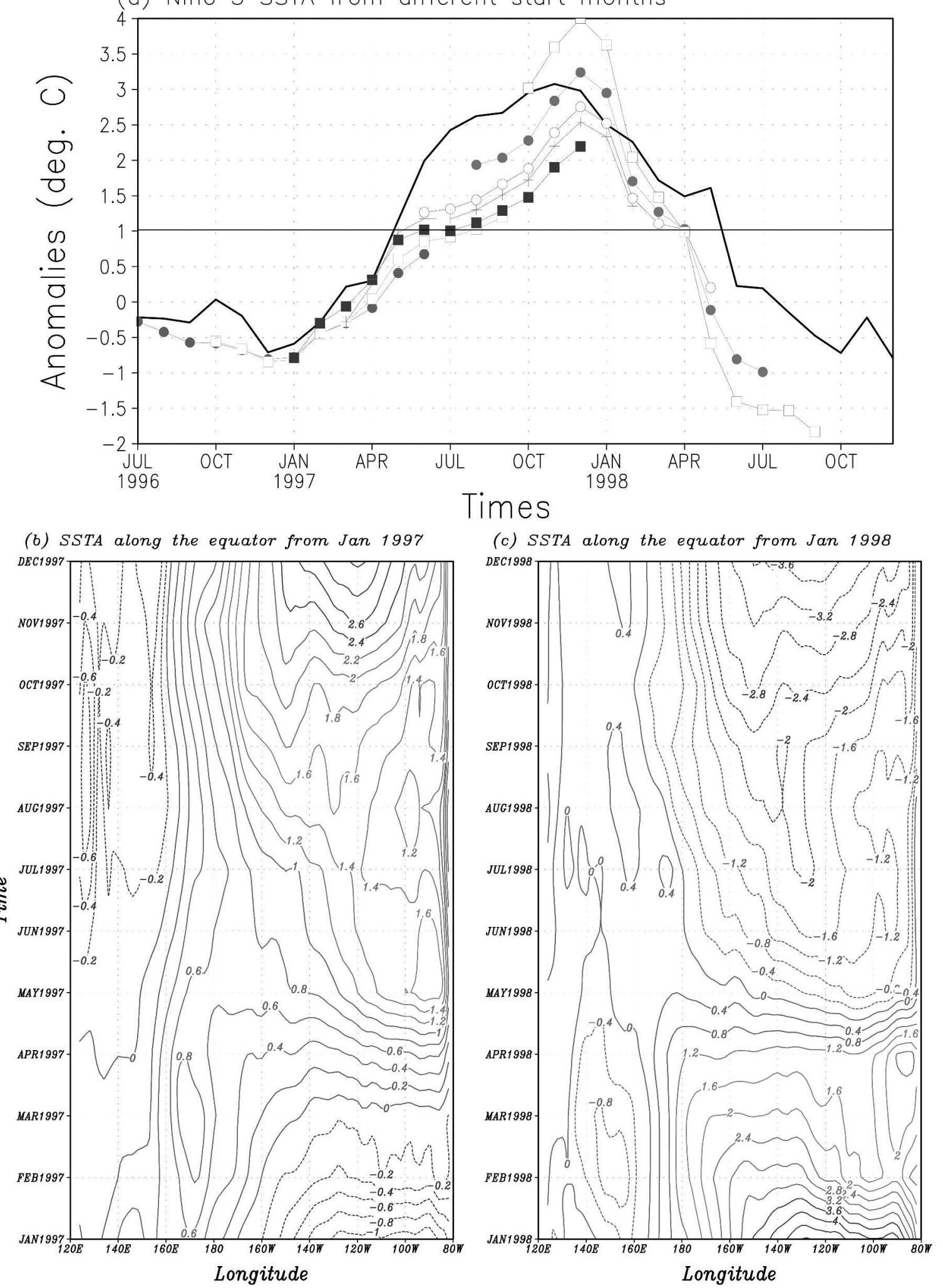

FIG. 19. (a) Observed (solid line) and predicted Niño-3 SST anomalies for the $1997 / 98$ El Niño; each predicted line is the trajectory of a 12-month forecast from different starting months. Longitude-time sections of predicted SST anomalies along the equator, which are a 12-month forecast initializing from (b) Jan 1997 and (c) Jan 1998, respectively. The contour interval is $0.5^{\circ} \mathrm{C}$ in (b) and (c). 
(a) 6 month lead times: Jan $1997=>$ June 1997

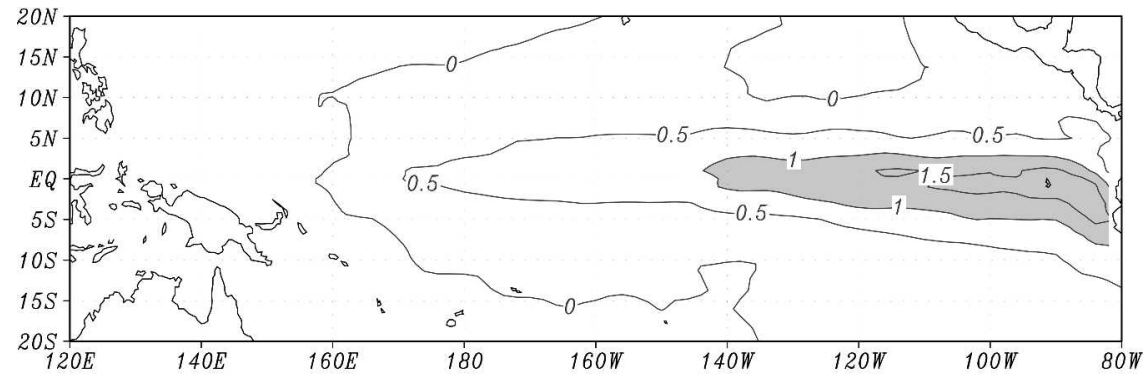

(b) 9 month lead times: Jan $1997=>$ Sep 1997

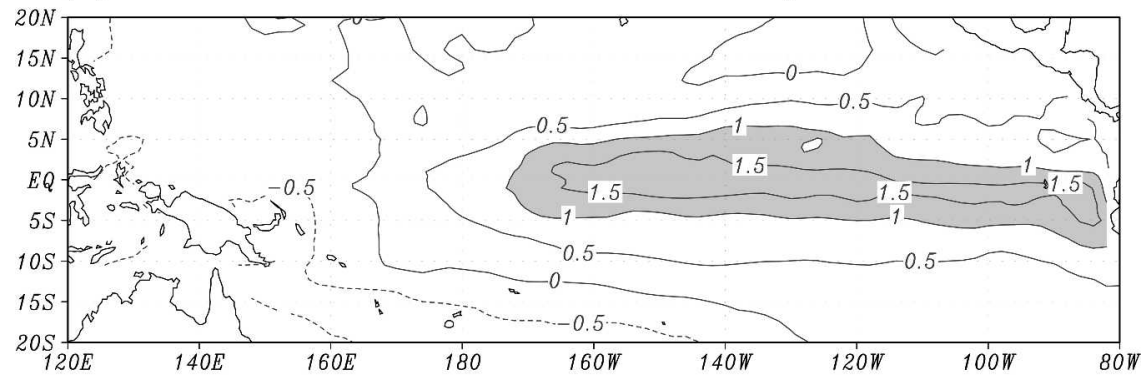

(c) 12 month lead times: Jan 1997 = Dec 1997

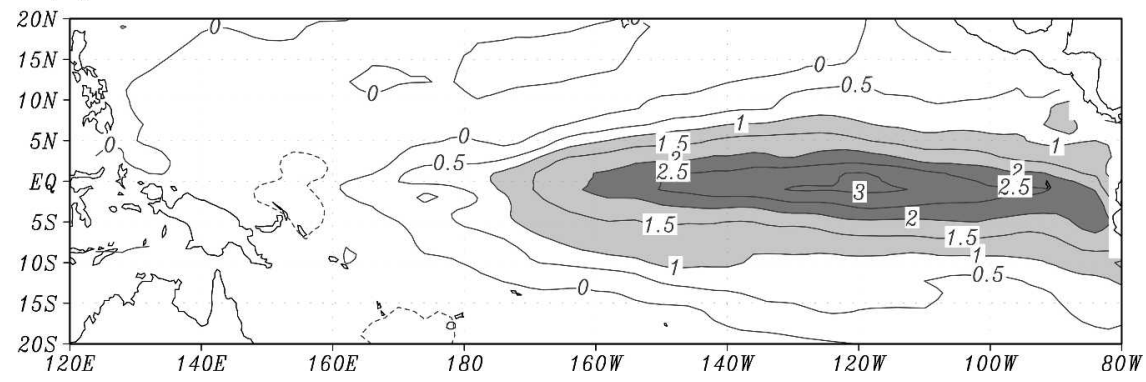

FIG. 20. Horizontal distributions of predicted SST anomalies from 1 Jan 1997 at 3-, 6-, and 9-month lead times, respectively. The contour interval is $0.5^{\circ} \mathrm{C}$.

though the periods selected for this forecast test may be too short to produce stable statistics for the coupled system, the artificial skill introduced through the two empirical $T_{e}$ and $\tau$ models that are constructed from historical data appears not to be significant.

\section{Discussions and conclusions}

A new ICM for El Niño simulation and prediction is described by improving its ocean dynamics and thermodynamics, which include varying stratification, certain nonlinear effects, and an empirical parameterization of $T_{e}$. Both accurate simulations of surface currents and of entrainment processes are key factors in accurate simulation of SST variability across the equatorial Pacific. In this paper, we have focused on empirical parameterizations of $T_{e}$.

There are two steps involved in deriving the empirical $T_{e}$ parameterization from historical data. First, an optimized estimate of $T_{e}$ is made from model simulations and observations via inverse calculation of the SST anomaly model. Second, a statistical relationship between the dominant variability patterns of SSH and $T_{e}$ is calculated in a reduced EOF space using regression analysis. This nonlocal scheme is able to better parameterize $T_{e}$ anomalies than other local schemes. An improved $T_{e}$ parameterization naturally leads to better depiction of the subsurface effect on SST variability by mean upwelling of anomalous subsurface temperature. As a result, SST anomaly simulations are significantly improved in the tropical Pacific Ocean.

The improved ocean model is coupled to a statistical atmospheric model that estimates wind stress anomalies based on an SVD analysis between observed SST anomalies and wind stress anomalies from ECHAM4.5 ensemble simulations. The seasonal variations of atmosphere and ocean feedbacks are taken into account by constructing seasonally varying versions for both the $T_{e}$ 
Correlation: Tau(Mon)-Te(Mon); 1997-2001

(a) Lead time 3 Months

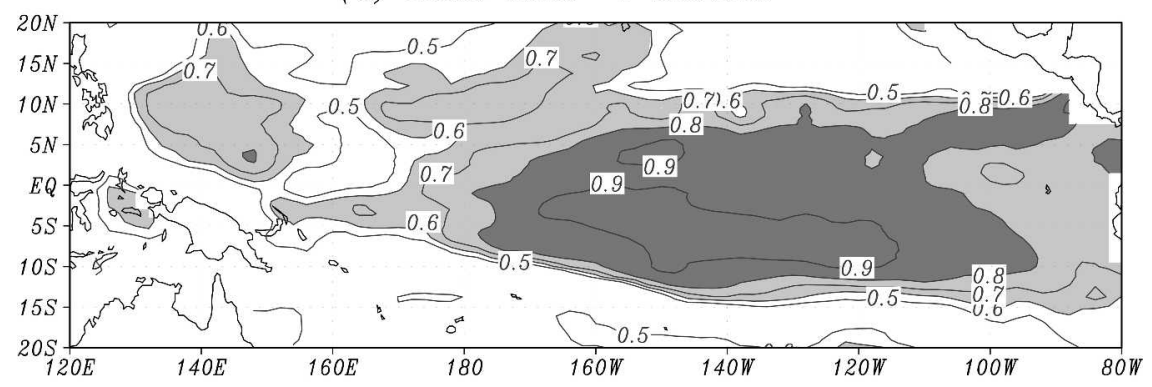

(b) Lead time 6 Months

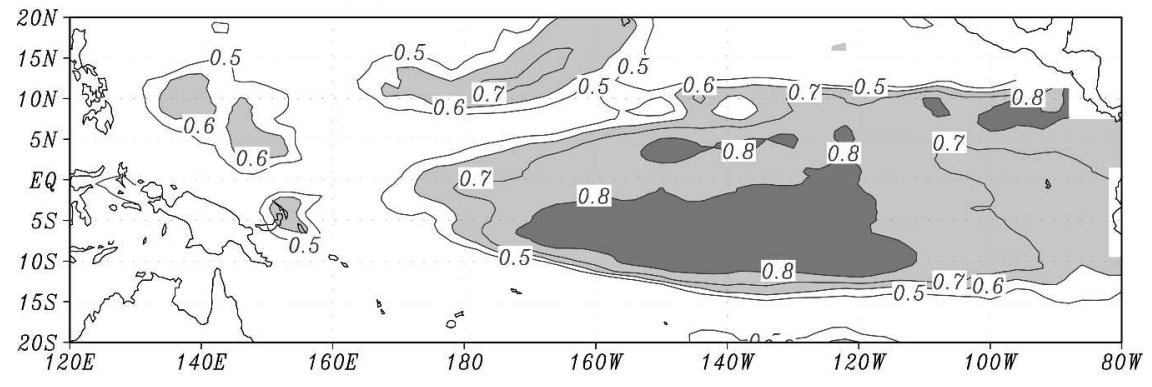

(c) Lead time 9 Months

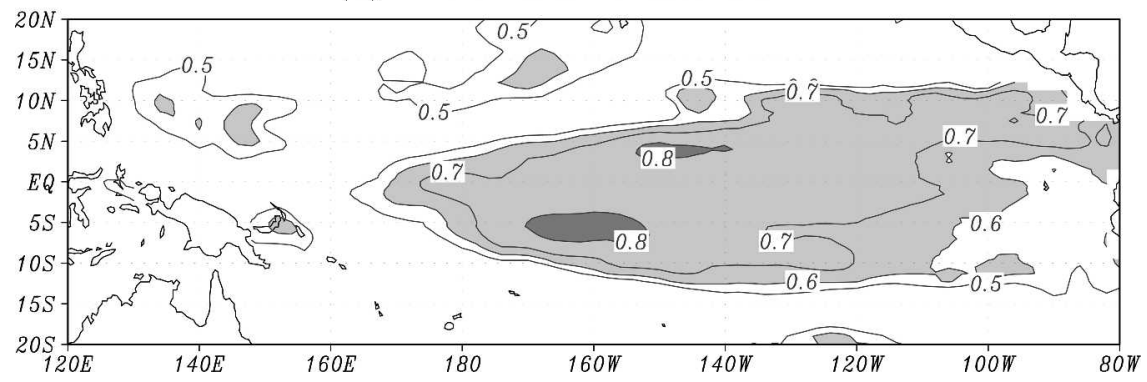

FIG. 21. Horizontal distributions of anomaly correlations between observed and predicted SST anomalies at 3-, 6-, and 9-month lead times, respectively. The results are obtained for all forecasts made during the period 1997-2001 regardless of their starting months. The contour interval is 0.1 .

and $\tau$ models. The coupled system exhibits a variety of behavior for a range of parameters that are in good agreement with observations, including a 3-4-yr oscillation period and a dominant standing pattern of SST variability on the equator. This coupled system does not have large systematic biases in terms of SST simulations.

Twelve-month-long hindcast experiments are performed with the model over the period 1963-97. The predictions are initialized using a coupled initialization technique that only uses observed SST anomalies. Wind stress anomalies are first constructed from observed SST anomalies via the ECHAM4.5-based $\tau$ model and are then used to integrate the ocean model up to the beginning of prediction time to generate initial conditions for the dynamical component. In addi- tion, the observed SST anomaly fields from the previous month are simply "injected" into the model at each start time of predictions. Compared to other documented coupled models, systematic errors of predicted SST anomalies are significantly smaller in this coupled model-apparently due to the optimized empirical $T_{e}$ parameterization. The skill is very high at short lead times, and so the model skill beats persistence at all lead times (out to 12 months) in the central equatorial Pacific. It seems that the injection of observed SST anomalies prior to each prediction is an important contributing factor to the improved skill of SST predictions at short lead time. The model is most successful in predicting central Pacific SST anomalies. However, model skill is strongly seasonal dependent, with significant skill loss during the boreal spring season. 
Cross-validation experiments are performed in which the training period for the empirical $T_{e}$ model and the prediction period do not coincide. These experiments show that independently and dependently trained models have approximately the same skill correlation over the central Pacific. The sensitivity to data periods selected for training $T_{e}$ models appear to be small, and the artificial skill is not significant. This has been further demonstrated in an independent prediction experiment for the period 1997-2002, including the 1997/98 El Niño. This experiment is yet a stricter test, since the $\tau$ model is now also trained on independent data. The model reproduces the transitions to the warming in the early 1997 and to cold phase in the spring of 1998 quite well. In particular, the model has a successful forecast for the onset of the 1997/98 El Niño initializing from the early 1997.

It is interesting to compare this ICM forecast system with the current and previous versions of the LDEO ICM forecast system (Cane et al. 1986; ZC87; Chen et al. 1995, 2000). Through various techniques, the LDEO forecast system has been improved from the early versions (LDEO1, LDEO2, LDEO3) to the latest version (LDEO4). The systematic biases in the earlier LDEO system have been successfully removed in the latest version (Chen et al. 2000). Our new ICM described here does not show obvious systematic bias in simulation and prediction of SST anomalies, perhaps due to the empirical parameterization of $T_{e}$. Although the LDEO system still has difficulty in initializing forecasts directly with SST observations, the present coupled system uses only observed SST fields to initialize predictions. Perhaps benefiting from this initialization procedure, the present ICM has better skill than LDEO4 at short lead times (below 4 months). Spatially, the two ICMs have different geographic skill dependence: our ICM has better skill in the central equatorial Pacific, but the LDEO4 is better in the eastern basin. At long lead times (beyond 9 months), the LDEO4 has better performance than ours particularly in the eastern equatorial Pacific.

The results described in this paper represent our preliminary attempts to develop and improve an intermediate system for better El Niño simulations and predictions. Further refinement and extension are underway. Some possible error sources are obvious in the system. For example, the empirical $\tau$ model is derived from ECHAM4.5 simulations forced by observed SST anomalies; potential errors in the atmospheric model are implicitly included in the construction of the empirical $\tau$ model. The $T_{e}$ parameterization scheme we developed empirically works best in the tropical central and western Pacific. In the eastern basin, where the
ZC87 scheme outperforms ours, there is clear room for improvement, and an optimal combination of these two schemes may potentially improve SST prediction across the entire basin. In addition, we only use observed SST in the initialization in this work; using more observed information in the prediction procedure in principle should constrain the system more effectively (i.e., comprehensive data assimilation and coupled initialization).

Acknowledgments. We are indebted to Stephane Raynaud for his help in setting up the ocean model at IRI. We thank D. Chen, D. DeWitt, Y. Tang, T. Barnston, P. Chang, A. J. Busalacchi, and R. Murtugudde for their comments. R. H. Zhang would like to thank P. Chang for his help in constructing the SVD-based statistical model. The ECHAM4.5 ensemble mean wind stress data are provided by Dr. M. Tippett at IRI, who is greatly appreciated. The authors wish to thank anonymous reviewers for their comments that helped to improve the original manuscript. This research is supported by the IRI and its sponsors, and by NSF Grant 25-74200-F0960 (RK) and NASA Grant 2574200-F5044 (RK).

\section{REFERENCES}

Barnett, T. P., M. Latif, N. Graham, M. Flugel, S. Pazan, and W. White, 1993: ENSO and ENSO-related predictability. Part I: Prediction of equatorial Pacific sea surface temperature with a hybrid coupled ocean-atmosphere model. J. Climate, 6, $1545-1566$.

Barnston, A. G., and C. G. Ropelewski, 1992: Prediction of ENSO episodes using canonical correlation analysis. J. Climate, 5, 1316-1345.

_ M. H. Glantz, and Y. He, 1999: Predictive skill of statistical and dynamical climate models in SST forecasts during the 1997-98 El Niño episode and the 1998 La Niña onset. Bull. Amer. Meteor. Soc., 80, 217-243.

Busalacchi, A. J., and J. J. O'Brien, 1980: The seasonal variability in a model of the tropical Pacific. J. Phys. Oceanogr., 10, 1929-1951.

Cane, M. A., S. E. Zebiak, and S. C. Dolan, 1986: Experimental forecast of El Niño. Nature, 321, 827-832.

Chang, P., L. Ji, and R. Saravanan, 2001: A hybrid coupled model study of tropical Atlantic variability. J. Climate, 14, 361-390.

Chen, D., S. E. Zebiak, A. J. Busalacchi, and M. A. Cane, 1995: An improved procedure for El Niño forecasting: Implications for predictability. Science, 269, 1699-1702.

_ , M. A. Cane, S. E. Zebiak, R. Canizares, and A. Kaplan, 2000: Bias correction of an ocean-atmosphere coupled model. Geophys. Res. Lett., 27, 2585-2588.

Ji, M., A. Leetmaa, and V. E. Kousky, 1996: Coupled model forecasts of ENSO during the 1980 and 1990s at the National Meteorological Center. J. Climate, 9, 3105-3120.

Jin, F.-F., and S.-I. An, 1999: Thermocline and zonal adjective feedbacks within the equatorial ocean recharge oscillator model for ENSO. Geophys. Res. Lett., 26, 2989-2992. 
Kalnay, E., and Coauthors, 1996: The NCEP/NCAR 40-Year Reanalysis Project. Bull. Amer. Meteor. Soc, 77, 437-471.

Kang, I.-S., and J.-S. Kug, 2000: An El Niño prediction system using an intermediate ocean and a statistical atmosphere. Geophys. Res. Lett., 27, 1167-1170.

Keenlyside, N., 2001: Improved modeling of zonal currents and SST in the tropical Pacific. Ph.D. thesis, Monash University, 193 pp.

— , and R. Kleeman, 2002: Annual cycle of the zonal currents in the equatorial Pacific. J. Geophys. Res., 107, 3093, doi:10.1029/2000JC000711.

Kirtman, B., Y. Fan, and E. K. Schneider, 2002: The COLA global coupled and anomaly coupled ocean-atmosphere GCM. $J$. Climate, 15, 2301-2320.

Kleeman, R., 1993: On the dependence of hindcast skill on ocean thermodynamics in a coupled ocean-atmosphere model. $J$. Climate, 6, 2012-2033.

Latif, M., and Coauthors, 1998: A review of the predictability and prediction of ENSO. J. Geophys. Res., 103, 14 375-14 393.

—- and Coauthors, 2001: ENSIP: The El Niño simulation intercomparison project. Climate Dyn., 18, 255-276.

Levitus, S., 1982: Climatological Atlas of the World Ocean. NOAA Prof. Paper 13, 173 pp. and 17 microfiche.

McCreary, J. P., 1981: A linear stratified ocean model of the equatorial undercurrent. Philos. Trans. Roy. Soc. London, 298, 603-635.

- and D. L. T. Anderson, 1991: An overview of coupled ocean-atmosphere models of El Nino and the Southern Oscillation. J. Geophys. Res., 96, 3125-3150.

Neelin, J. D., and F.-F. Jin, 1993: Modes of interannual tropical ocean-atmosphere interaction a united view. Part II: Analytical results in the weak-coupling limit. J. Atmos. Sci., 50, 3504-3522.

Reynolds, R. W., N. A. Rayner, T. M. Smith, D. C. Stokes, and W. Wang, 2002: An improved in situ and satellite SST analysis for climate. J. Climate, 15, 1609-1625.
Rosati, A., K. Miyakoda, and R. Gudgel, 1997: The impact of ocean initial conditions on ENSO forecasting with a coupled model. Mon. Wea. Rev., 125, 754-772.

Schneider, E. K., D. G. DeWitt, A. Rosati, B. P. Kirtman, L. Ji, and J. J. Tribbia, 2003: Retrospective ENSO forecasts: Sensitivity to atmospheric model and ocean resolution. Mon. Wea. Rev., 131, 3038-3060.

Stockdale, T. N., D. L. T. Anderson, J. O. S. Alves, and M. A. Balmaseda, 1998: Global seasonal rainfall forecasts using a coupled ocean-atmosphere model. Nature, 392, 370-373.

Syu, H.-H., and J. D. Neelin, 2000: ENSO in a hybrid coupled model. Part II: Prediction with piggyback data assimilation. Climate Dyn., 16, 35-48.

,-- , and D. Gutzler, 1995: Seasonal and interannual variability in a hybrid coupled GCM. J. Climate, 8, 2121-2143.

Tang, Y., and W. W. Hsieh, 2002: Hybrid coupled models of the tropical Pacific: II ENSO prediction. Climate Dyn., 19, $343-$ 353.

Wang, W., and M. J. McPhaden, 2000: The surface-layer heat balance in the equatorial Pacific Ocean. Part II: Interannual variability. J. Phys. Oceanogr., 30, 2989-3008.

Zebiak, S. E., and M. A. Cane, 1987: A model El Niño/Southern Oscillation. Mon. Wea. Rev., 115, 2262-2278.

Zhang, R.-H., and S. Levitus, 1997: Interannual variability of the coupled tropical Pacific ocean-atmospheric system associated with the El Niño-Southern Oscillation. J. Climate, 10, 1312-1330.

— , S. E. Zebiak, R. Kleeman, and N. Keenlyside, 2003: A new intermediate coupled model for El Niño simulation and prediction. Geophys. Res. Lett., 30, 2012, doi:10.1029/2003GL018010.

_ , R. Kleeman, S. E. Zebiak, N. Keenlyside, and S. Raynaud, 2005: An empirical parameterization of subsurface entrainment temperature for improved SST simulations in an intermediate ocean model. J. Climate, 18, 350-371. 